\title{
MODELING AND SIMULATION FOR SUPPLY CHAIN FINANCE UNDER UNCERTAIN ENVIRONMENT
}

\author{
Wei JIN ${ }^{(D)} 1$, Chengfu WANG ${ }^{* 2}$ \\ ${ }^{1}$ School of Finance, Zhejiang University of Finance and Economics, \\ Hangzhou, 310018, China \\ ${ }^{2}$ School of Information, Zhejiang University of Finance and Economics Dongfang College, \\ Haining, 314408, China
}

Received 28 February 2019; accepted 08 January 2020

\begin{abstract}
This paper studies the role of factoring in a bilateral supply chain, where both the supplier and retailer are financially constrained. Applying the stylized Stackelberg game, we analytically present that the supplier's capital shortage limits the advantage of trade credit provided to the retailer. To overcome this limitation, we design a hybrid strategy composing of trade credit and factoring, and then investigate how the supplier uses factoring strategy to achieve the best performance. Analytical and numerical results show that: (1) each supply chain partner can benefit from factoring, and the benefits depend on operational and financial characteristics; (2) in a fairly priced factoring market, bankruptcy costs reduce the benefits of factoring, but does not change the dominance of full factoring; (3) in a strategically priced factoring market, partial factoring may dominate full factoring. Managerially, our study implies that a supplier may benefit from dividing his accounts receivable when facing a factor with a strong pricing ability.
\end{abstract}

Keywords: operations research, strategy, decision making, game theory.

JEL Classification: C44, C72, D24, E23.

\section{Introduction}

As a short-time financing method extended from suppliers to their buyers, trade credit is widely adopted in business practice. Offering trade credit may be a way to boost sales, but many small suppliers find it hard to efficiently supply their buyers, since offering trade credit occupies their limited working capital. Such inefficiency eventually makes a detrimental effect on the profitability and competitiveness of the whole supply chain. To address the problem, some suppliers in practice are employing the factoring scheme, in which firms sell their accounts receivable (AR) to a factor at a discount for immediate cash. On the other hand, the factor collects the payment from the buyer when the credit is due.

${ }^{\star}$ Corresponding author. E-mail: chengfuwang@yeah.net

This is an Open Access article distributed under the terms of the Creative Commons Attribution License (http://creativecommons. org/licenses/by/4.0/), which permits unrestricted use, distribution, and reproduction in any medium, provided the original author and source are credited. 
Indeed, factoring is an attractive tool to raise working capital for many small firms, especially when banks have tightened up cash supply. We take the manufacture of clothing in the textile industry as an example (see Kiisel, 2013). According to the convention of this industry, clothing manufacturers often wait a long time to collect the payment from the department store chains. To mitigate the cash flow issues during the waiting time, these manufacturers generally turn to factors to handle their AR. Factors, after deducting interest and fees, pay the manufacturers a portion of AR immediately. However, despite the wide usage of factoring, we also notice that some small firms hesitate to factor their AR. Hence, several important questions arise. (1) Does a capital-constrained supplier always have an incentive to factor AR? If so, how to sell AR, partially or fully? (2) How do supply chain firms make the joint operational and financing decisions when factoring is incorporated into trade credit? (3) Whether the incorporation of factoring can enhance supply chain performance as well as the financing efficiency of trade credit.

To address such questions, we use a stylized supply chain model in which a supplier sells to a retailer facing uncertain demand. The retailer runs into financial difficulty and has to delay payment to the end of selling season (in other words, the retailer utilizes trade credit to finance inventory). On the other hand, the supplier is endowed with limited capital, which may be insufficient to support optimal production. To mitigate capital constraint, the supplier can sell his AR to a factor for immediate cash. The factoring is priced fairly or strategically, depending on the competition type of factoring market. For example, the fairly pricing scheme is valid for a completely competitive market and the strategically pricing scheme exists in the monopoly factoring market. Based on the ways of factoring, we consider three financing strategies.

- Single trade credit (STC): The retailer uses trade credit provided by the supplier, whereas the supplier only uses internal capital to support production.

- Hybrid strategy with full factoring (HFF): The supplier extends trade credit to the retailer, and sells the whole AR to a factor. When the credit is due, the retailer pay obligations to the factor based on limited-liability principle.

- Hybrid strategy with partial factoring (HPF): The supplier extends trade credit to the retailer, and sells a portion of AR to a factor. To better understand the role of factoring, we assume that the supplier's AR to be divisible. This is attainable through securitizing the supplier's AR. Under HPF, we allow the arbitrary allocation of the retailer's credit risk.

Our work contributes to the literature in two aspects. First, we propose theoretical models to capture the role of factoring in enhancing supply chain performance, and particularly investigate how the supplier divides AR to achieve the best performance. Second, we extend the analysis by allowing the factoring market to be imperfect and examine how the bankruptcy cost and the factor's financing ability influence the choice of financing strategy. The main findings are as follows. The hybrid strategy with factoring indeed serves as a powerful tool to improve cash flows of the supply chain, and creates value for supply chain partners. In addition, the benefits of factoring critically depend on operational and financial characteristics, such as the bankruptcy costs, supply chain capital level and the factor's pricing ability. Furthermore, the divisibility of the supplier's AR may be needed, especially when the factor has a strong pricing ability. 


\section{Literature review}

Our work fits in supply chain finance (SCF) and is closely related to two streams of literature: external financing and trade credit.

First, there is an extensive literature on supply chain external financing, among which bank credit has been recognized as the main one of external financing. Within bank credit literature, a number of papers investigate the joint operational and financing decisions, including Buzacott and Zhang (2004), Dada and $\mathrm{Hu}$ (2008), Kouvelis and Zhao (2011), Gong et al. (2014), Lin and Xiao (2018). Some of the results in these papers show that firms' financial considerations are particularly important for operational decisions. Specifically, some factors (such as agency issues, bankruptcy costs, information asymmetry) make operational and financing decisions interact in different ways. Recently, a few papers have begun to examine external credit from e-commerce platform (e.g., Chen \& Zhang, 2019; Wang et al., 2019), or the combination of bank loan and other credit (e.g., Jin et al., 2018; Huang et al., 2019; Lu et al., 2019).

Earlier research on factoring focuses on empirical studies. For example, several studies (e.g., Mian \& Smith, 1992; Sopranzetti, 1998; Klapper, 2006; Do, 2018, etc) have explored the mechanism or value of factoring strategy in financing small and medium enterprises. Soufanis (2002) empirically finds that factoring serves as a source of finance for working capital and is not universally available. Recently, some researchers in operation management have begun to investigate the role of factoring within a supply chain setting. Among them, Montibeller et al. (2007) design a method for factoring company to evaluate the relevant risk of buying AR. With the assumption of constant demand, Li and Gu (2018) compare two factoring schemes from the perspectives of a capital-constrained firm and the factors. Differing from the existing factoring work, we study the role of factoring in enhancing supply chain performance under demand uncertainty. More importantly, the factoring in our model is allowed to be separated, which is prevalent in practice in the form of securitization but not considered in operations management (OM) research.

Second, the research on trade credit is extensive. A thorough literature review can be found in Seifert et al. (2013). We restrict our attention on the role of trade credit in inventory financing. In this area, Zhou et al. (2015) show a capital-constrained retailer's optimal policy under a partial trade credit. Chod (2016) illustrates trade credit financing under the scenario that a financially constrained retailer procures inventory of two products. Most recently, Zhan et al. (2019) design an adjusted trade credit contract for a supply chain with a financially constrained retailer. Chod et al. (2019) present that the competition among suppliers could lead to free rider problem and affect supplier's willingness to provide trade credit. Li et al. (2019) use a heuristic algorithm to determine trade credit terms in multi-stage setting. By building a trade credit model with an opportunistic retailer, Zha et al. (2019) investigate how trade credit contract coordinates supply chain, with or without information symmetry. Most of the above papers assume the supplier in trade credit financing to be bigsized, and hence can obtain additional earnings by asking interest rate. However, this paper is based on the context that a small supplier is capital-constrained and finances his production through selling his AR. 
This paper is closed related to Kouvelis and Zhao $(2012,2018)$ and Yang and Birge (2017). Kouvelis and Zhao (2012) establish the optimal trade credit contract for a supplier selling to capital-constrained retailer, under which the supplier fully finances the retailer using exclusive trade credit. Further, Kouvelis and Zhao (2018) argue that the optimal financing solution needs adjustion when the supplier's credit rating is taken into account. They find that the supplier with low credit rating will induce the retailer to use the mixture of trade credit and bank loan. Yang and Birge (2017) consider the impact of bankruptcy costs on the design of optimal trade credit contract and the retailer's financing structure. Motivated by the three papers, we also investigate the issues of trade credit and bankruptcy costs, but have different problem scenarios and results. First, we focus on the scenario that the retailer is restricted or not willing to access bank loan, and the supplier sells his AR to finance the supply chain. We explore how the supplier divides his AR to attain the best performance. Second, we consider the strategic factoring pricing and find that the factor's pricing ability acts as a driven factor to affect the division of AR and the retailer's financing structure.

\section{Notation and assumptions}

Market: Consider a dyadic supply chain consisting of one supplier ("he") and one retailer ("she"), where both firms are small-sized. The retailer purchases $q$ unit product from the supplier at a wholesale price $w$ prior to the selling season. The demand $X$ during the selling season is uncertain, with a density function $f(x)$ and a cumulative distribution function $F(x)$. Let $g(x)=x h(x)$ be the generalized failure rate of the demand $X$, where $h(x)=f(x) / \bar{F}(x)$ is the failure rate. As in Lariviere and Porteus (2001), we assume that the demand distribution has an increasing failure rate property. The product we consider is perishable and has no salvage value at the end of selling season. To simplify the exposition, the penalty cost for the unsatisfied demand is ignored and the risk-free rate is normalized to zero. The retail price is normalized to 1 for brevity. The notation throughout this paper are summarized in Table 1 .

Trade credit: The supplier and retailer are endowed with limited capital level $B_{S}$ and $B_{R}$, respectively. The retailer's capital level is assumed to be insufficient to support the desired procurement. This retailer uses trade credit to mitigate capital constraint. We assume that the trade credit extended to the retailer has no deferred cost, which is the business standard in some industries with intense competition (Peura et al., 2017). The supplier may suffer capital constraint because of the retailer's delay payment. The hybrid of trade credit and factoring can be used to alleviate the supplier's and retailer's capital restrictions. Specifically, the retailer uses trade credit provided by the supplier, and the latter sells his account receivable (AR) fully or partially at a discount to a factor for immediate cash.

Factoring Policy: Throughout this paper, we focus on the factoring without recourse. We introduce a parameter $\alpha \in[0,1]$ to specify the factoring ratio of the AR. Three types of factoring arise based on the value of $\alpha$ : no factoring, partial factoring and full factoring. Correspondingly, there exist three kinds of financing strategies. Under the single trade credit strategy $(\alpha=0)$, the supplier has double roles, namely, product seller and creditor. Under the hybrid strategy with full factoring $(\alpha=1)$, the supplier only acts as a product seller. Under the hybrid strategy with partial factoring $(\alpha \in(0.1))$, the supplier also has double roles, but shares the retailer's credit risk with a factor. 
Table 1. Summary of notation

\begin{tabular}{|c|l|}
\hline Symbol & Definition \\
\hline$B_{S}$ & supplier's initial capital level \\
\hline$B_{R}$ & retailer's initial capital level \\
\hline$c$ & supplier's marginal production cost \\
\hline$w$ & wholesale price set by the supplier \\
\hline$q$ & retailer's order quantity \\
\hline$\delta$ & price discount rate set by the factor, $\delta \in[0.1]$ \\
\hline$\alpha$ & factoring ratio of the supplier's accounts receivable \\
\hline$X$ & market demand \\
\hline$f(\cdot)$ & probability density function of the demand distribution \\
\hline$F(\cdot)$ & cumulative distribution function of the demand distribution \\
\hline $\bar{F}(\cdot)$ & complementary cumulative distribution function of the demand distribution \\
\hline$y_{i}$ & trade credit size/amount with and without factoring strategy, where $i=0.1$ \\
\hline $\mathbb{E}(\cdot)$ & expectation operator \\
\hline$\pi_{i}^{R}$ & retailer's expected profit \\
\hline$\pi_{i}^{S}$ & supplier's expected profit \\
\hline
\end{tabular}

Limited liability assumption: Following the convention in some operations-finance literature (see Kouvelis \& Zhao, 2012), we assume that the retailer has limited liability and only uses sales revenue to repay her obligations. Thus, the retailer defaults the remaining debt if her sales revenue is unable to cover the obligation. In addition, we suppose that the retailer uses trade credit extended by the supplier without interest rate, which has been examined empirically and theoretically (Giannetti et al., 2011; Kouvelis \& Zhao, 2012).

Fairly priced factoring assumption: Assume that the factoring is fairly priced, i.e., the factor is in a fully competitive factoring market. Under this assumption, the factor's operational purpose is to break even. This assumption allows us to focus on the interactions between trade credit and factoring without introducing additional complexity. Section 5 relaxes this assumption and discusses the scenario that the factoring is priced strategically.

Sequence of events: The supplier and retailer play a Stackelberg game, where the supplier acts as the leader and the retailer acts as the follower. (1) At the beginning of selling season, the supplier offers a wholesale price $w$ to the retailer, who then procures a quantity of $q>0$, and pays $B_{R}$ immediately. The supplier then has an accounts receivable (AR) with value of $w q-B_{R}$. He sells a portion (or the whole) of his AR to a factor at a discount rate $\delta$. (2) At the end of selling season, the retailer reaps sales revenue and repays the credit to the both of the factor and supplier (or only the factor), depending on the factoring ratio. Figure 1 illustrates the sequence of events.

In this paper, we focus on investigating whether and how the supplier uses factoring policy when trade credit is adopted. The following mathematical symbol and operations are used throughout this paper: $[a]^{+}=\max (0, a),[a-b]^{+}=a-\min (a, b)$ for any $a, b \in \mathcal{R}$. 


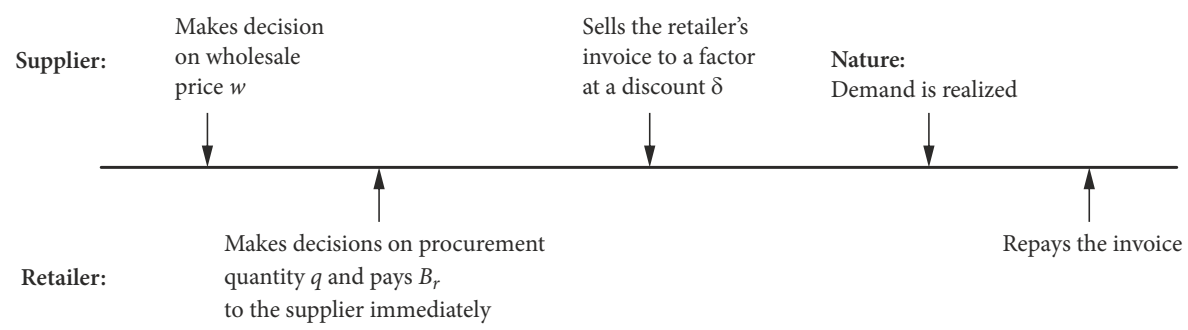

Figure 1. Sequence of events

\section{Single trade credit strategy}

In this section, a benchmark scenario with no factoring is considered. The capital-constrained retailer uses the trade credit extended by the supplier, while the latter only uses his internal capital as well as the prepayment from the retailer to support production. Recall that the supplier and retailer play a Stackelberg game, we thus adopt backward induction to solve the optimal decisions.

First, we analyze the retailer's decision. At the beginning of the production, the retailer orders a quantity of $q_{0}$ from the supplier. Due to capital constraints problem, she only pays an amount of $B_{R}$ to the supplier and delays the amount of $w_{0} q_{0}-B_{R}$ to the end of selling season. Thus, the retailer's optimization problem can be formulated as:

$$
\begin{aligned}
& \quad \max _{q_{0}} \pi_{0}^{R}\left(q_{0}\right)=\mathbb{E}\left[\mathrm{S}\left(q_{0}\right)-\left(w_{0} q_{0}-B_{R}\right)\right]^{+}-B_{R}, \\
& \text { s. t. } w_{0} q_{0}>B_{R} .
\end{aligned}
$$

In Eq. (1), $S\left(q_{0}\right)=1 \cdot \min \left(X, q_{0}\right)$ represents the retailer's sales revenue at the end of selling season. Based on the limited-liability assumption, the retailer's gains after paying liability (i.e. the remaining amount of the payment to the supplier) should be $\left[S\left(q_{0}\right)-\left(w_{0} q_{0}-B_{R}\right)\right]^{+}$. In other words, if the realized demand is sufficient high, the retailer can fully repay the debt, and her remaining gains after payment are $S\left(q_{0}\right)-\left(w_{0} q_{0}-B_{R}\right)$; otherwise, she defaults and all realized revenues are transferred to the supplier. Thus, in default case, the retailer obtains nothing. Constraint (2) reflects that trade credit is adopted by the retailer.

Proposition 1. Given the wholesale price $w_{0}$, (1) the retailer's order quantity denoted by $q_{0}\left(w_{0}\right)$ is determined by the following equation,

$$
\bar{F}\left(q_{0}\right)=w_{0} \bar{F}\left(w_{0} q_{0}-B_{R}\right) .
$$

(2) $q_{0}\left(w_{0}\right)$ decreases with $w_{0}$ and $B_{R}$.

Next, we consider the optimal wholesale price decision. In anticipation of the retailer's response function $q_{0}\left(w_{0}\right)$, the supplier determines the wholesale price to maximize his expected profit given as follows.

$$
\pi_{0}^{S}\left(w_{0}\right)=\mathbb{E}\left[\min \left(\mathrm{S}\left(q_{0}\right),\left(w_{0} q_{0}-B_{R}\right)\right)\right]+B_{R}-c q_{0} .
$$

s. t. $c q_{0} \leq B_{R}+B_{S}$ (supply chain capital constraint). 
The supplier's expected profit includes three parts. The first part $\min \left(\mathrm{S}\left(q_{0}\right),\left(w_{0} q_{0}-B_{R}\right)\right)$ is the cash flow obtained from the retailer at the end of selling season. In other words, the supplier obtains $w_{0} q_{0}-B_{R}$ when the retailer can fully repay liability; otherwise, the retailer defaults and the supplier only obtains $\mathrm{S}\left(q_{0}\right)$. The second term $B_{r}$ is the payment from the retailer at the beginning of selling season. The third term $c q_{0}$ is the production costs. Considering that the value of the first term may be sufficiently small, the supplier thus suffers risk of getting negative profit. Hence, the supplier need to price appropriately by trading off the profit and the underlying risk.

In the following analysis, we denote $\left(w^{N}, q^{N}\right)$ as the solutions to Eq. (5),

$$
\left\{\begin{array}{l}
\bar{F}\left(q_{0}\right)\left[1-g\left(q_{0}\right)\right]=c\left[1-w_{0} q_{0} h\left(y_{0}\right)\right], \\
\bar{F}\left(q_{0}\right)=w_{0} \bar{F}\left(y_{0}\right),
\end{array}\right.
$$

where $g\left(q_{0}\right)=\frac{q_{0} f\left(q_{0}\right)}{\bar{F}\left(q_{0}\right)}$ and $h\left(y_{0}\right)=\frac{f\left(y_{0}\right)}{\bar{F}\left(y_{0}\right)}$. Then, we have Proposition 2 .

Proposition 2. Let $\bar{q}=\left(B_{s}+B_{R}\right) / c$, there exists a boundary line $\bar{B}_{S}\left(B_{R}\right) \triangleq c q^{N}-B_{R}$ such that, (1) the optimal operational decisions are $\left(w_{0}^{*}, q_{0}^{*}\right)=\left(w^{N}, q^{N}\right)$ when $B_{S} \geq \bar{B}_{S}\left(B_{R}\right)$; (2) otherwise, $\left(w_{0}^{*}, q_{0}^{*}\right)=(\bar{w}, \bar{q})$, where $\bar{w}=\bar{F}(\bar{q}) / \bar{F}\left(\bar{w} \bar{q}-B_{R}\right)$ is the optimal wholesale price when supply chain capital constraint is binding.

In Proposition 2, $\bar{B}_{S}\left(B_{R}\right)$ defines the supplier's boundary between being capital-constrained and being capital-unconstrained. The supplier's capital is sufficient to support the optimal production quantity $q^{N}$ when $B_{S} \geq \bar{B}_{S}\left(B_{R}\right)$. However, the supplier is subject to capital constraints when $B_{S}<\bar{B}_{S}\left(B_{R}\right)$. Define the financing ability of trade credit as the ratio of realized trade credit size to the optimal trade credit size. Clearly, the supplier only produces the quantity of $\left(B_{S}+B_{R}\right) / c$ if the supplier suffers capital constraints. As a result, the financing ability of trade credit is reduced.

\section{Hybrid strategy with factoring}

\subsection{Joint operational and financing decisions}

In this section, we analyze a hybrid strategy with factoring, under which the supplier provides trade credit to the retailer and simultaneously sells AR partially or fully to a factor. Define $\alpha \in(0.1]$ as the factoring ratio of AR and $y_{1}$ as the total value of AR. Then, the retailer owes $\alpha y_{1}$ to the factor and $(1-\alpha) y_{1}$ to the supplier. In essence, the parameter $\alpha$ measures how the demand risk is allocated between the supplier and the factor.

First, we consider the retailer's optimization problem. Given the wholesale price set by the supplier, the retailer decides the order quantity by solving the following optimization problem:

$$
\max _{q_{1}} \pi_{1}^{R}\left(q_{1}\right)=\mathbb{E}\left[S\left(q_{1}\right)-y_{1}\right]^{+}-B_{R} .
$$

Above, $S\left(q_{1}\right)=1 \cdot \min \left(X, q_{1}\right)$ represents the retailer's sales revenue under factoring scenario. Clearly, the retailer's expected profit, as well as the resulting response function is not impacted by the factoring ratio. 
Next, we focus on the supplier's optimization problem. The supplier's revenue includes three parts: (i) upfront payment from the retailer $\left(B_{R}\right)$; (ii) upfront payment from the factor $\left((1-\delta) \alpha y_{1}\right)$; (iii) delay payment from the retailer. Similar as Yang and Birge (2017), we assume that external credit (i.e., the credit from factor in this paper) is senior to internal credit (i.e., the credit from the supplier) when the retailer defaults. Therefore, the third part can be summarized as follows:

$$
\text { Delay payment part }=\left\{\begin{array}{l}
0, \quad X<\alpha y_{1} \\
1 \cdot X-\alpha y_{1}, \quad \alpha y_{1} \leq X<y_{1} \\
(1-\alpha) y_{1}, \quad X \geq y_{1}
\end{array}\right. \text {. }
$$

Mathematically, the delay payment part can be rewritten as $\left[1 \cdot \min \left(X, y_{1}\right)-\alpha y_{1}\right]^{+}$. Then, the supplier's optimization problem can be formulated as:

$$
\begin{array}{ll} 
& \max _{w_{1}} \pi_{1}^{S}\left(w_{1}\right)=(1-\delta) \alpha y_{1}+B_{R}-c q_{1}+\mathbb{E}\left[1 \cdot \min \left(X, y_{1}\right)-\alpha y_{1}\right]^{+}, \\
\text {s. t. } & c q_{1} \leq B_{S}+B_{R}+(1-\delta) \alpha y_{1}, \quad \text { (supply chain capital constraint); } \\
& \mathbb{E}\left[\min \left(S\left(q_{1}\right), \alpha y_{1}\right)\right]=(1-\delta) \alpha y_{1} . \text { (fairly factoring pricing equation). }
\end{array}
$$

Constraint (8) represents that the supplier's upfront payment plus internal capital should cover his production costs. Eq. (9) represents the factors' break-even condition under the scenario with partial factoring, where $\min \left(\mathrm{S}\left(q_{1}\right), \alpha y_{1}\right)$ is the factor's revenue at the end of selling season. After simplification, we obtain the optimal decisions when factoring is adopted.

Proposition 3. Given $B_{S}<\bar{B}_{S}\left(B_{R}\right)$ and a factoring ratio $\alpha \in(0.1]$, there exists a unique factoring threshold $\bar{\alpha}\left(B_{S}, B_{R}\right)>0$ that solves the equation $\bar{B}_{S}\left(B_{R}\right)-B_{S}=\int_{0}^{\alpha\left(w^{N} q^{N}-B_{R}\right)} \bar{F}(x) d x$. (1) the optimal operational decisions are $\left(w_{1}^{*}, q_{1}^{*}\right)=\left(w^{N}, q^{N}\right)$ when $\alpha \geq \bar{\alpha}\left(B_{S}, B_{R}\right)$; otherwise, $\left(w_{1}^{*}, q_{1}^{*}\right)=\left(\bar{w}_{\alpha}, \bar{q}_{\alpha}\right)$, where $\bar{q}_{\alpha}=\left(B_{s}+B_{R}+\int_{0}^{\alpha\left(\bar{w}_{\alpha} \bar{q}_{\alpha}-B_{R}\right)} \bar{F}(x) d x\right) / c$ and $\bar{w}_{\alpha}=\bar{F}\left(\bar{q}_{\alpha}\right) /$ $\bar{F}\left(\bar{w}_{\alpha} \bar{q}_{\alpha}-B_{R}\right)$; (2) the optimal discount rate is $\delta_{1}^{*}=1-\int_{0}^{\alpha y_{1}^{*}} \bar{F}(x) d x / \alpha y_{1}^{*}$, where $y_{1}^{*}=w_{1}^{*} q_{1}^{*}-B_{R}$ is the value of AR.

As stated in Proposition 3, the division of the supplier's AR exhibits a threshold effect. More specifically, when the factoring ratio is fairly low (i.e., $\left.\alpha<\bar{\alpha}\left(B_{S}, B_{R}\right)\right)$, the supplier's capital still limits the operational decisions. However, when the factoring ratio is relatively high (i.e., $\alpha \geq \bar{\alpha}\left(B_{S}, B_{R}\right)$ ), the supplier's capital constraints does not bind and hence the retailer can order the quantity of $q^{N}$. In this case, the factoring ratio does not have any impact on the optimal operational decisions, as well as the supply chain profits. For the threshold value $\bar{\alpha}\left(B_{S}, B_{R}\right)$, it can be shown that $\partial \bar{\alpha}\left(B_{S}, B_{R}\right) / \partial B_{S}<0$ and $\partial \bar{\alpha}\left(B_{S}, B_{R}\right) / \partial B_{R}<0$. This means that a smaller factoring ratio of $A R$ is required to support the capital-unconstrained operations as the supply chain has higher capital level.

In the subsequent analysis, we first consider analytical properties regarding to the optimal decisions and supply chain performance for the case of $\bar{\alpha}\left(B_{S}, B_{R}\right) \leq c$, which corresponds to the practical scenario that the supply chain is slightly capital-constrained. 
Proposition 4 (Impact of the factoring ratio $\alpha$ ). For a slightly capital-constrained supply chain (i.e., $\bar{\alpha}\left(B_{S}, B_{R}\right) \leq c$ ), (1) when $\alpha \geq \bar{\alpha}\left(B_{S}, B_{R}\right)$, the optimal production quantity and wholesale price, as well as the supplier's and retailer's expected profits keep constant, whereas the optimal discount rate increases with $\alpha$; (2) when $\alpha<\bar{\alpha}\left(B_{S}, B_{R}\right)$, the optimal production quantity and discount rate, as well as the supplier's and retailer's expected profits increase with $\alpha$, whereas the optimal wholesale price decreases with $\alpha$.

Analytical results from Proposition 4 states that the supplier is able to use factoring strategy to finance the whole supply chain and improve each partner's performance. In essence, factoring ratio $\alpha$ reflects the risk sharing ratio that the factor bears. Higher $\alpha$ means that the supplier transfers more risk to the factor. In turn, the factor charges a higher financing rate (or equivalently, a higher discount rate). Intuitively, the supplier may divide AR to reduce financing costs when he has low capital requirement. Proposition 4 implies that the supplier with small financing needs cannot benefit from dividing AR. We give more specific discussions on this point in subsection 4.2, please see Corollaries 1 and 2.

For the case of $\bar{\alpha}\left(B_{S}, B_{R}\right)>c$, i.e., the supply chain is heavily short of capital, it is highly intractable to give analytical properties. Thus, we resort to numerical experiments to test whether the results presented in Proposition 4 can be extended to this case. In order to ensure the robustness of model parameters, such as the demand distribution, supply chain capital level, and unit production cost, we make a large number of computational simulations. More specifically, we test a series of demand distributions, like Normal, Gamma, Weibull and Exponential distributions, and also continuously vary the parameters of a given distribution. Additionally, both the supplier's and retailer's capital level is varied from 0 to $c \bar{F}^{-1}(c)$ with one step; the unit production cost is varied from 0.05 to 0.95 with 0.01 steps. In sum, all our simulations consistently present that the results in the case of $\bar{\alpha}\left(B_{S}, B_{R}\right) \leq c$ can be extended to that in the case of $\bar{\alpha}\left(B_{S}, B_{R}\right)>c$.

Next, we use simulation example 1 to present our observational results.

Simulation example 1. Assume that the demand follows an Exponential distribution with mean value 1000 . The supplier and retailer are endowed with capital level as $B_{S}=10$ and $B_{R}=50$. Consider that the retail price is normalized to one throughout this paper, thus the marginal production cost should be smaller than one, assume $c=0.4$. Parameter $\alpha$ increases from zero to one with 0.01 steps.

Figure 2 confirms the validation of Proposition 3 and 4.That is, there exists a threshold value (this value equals to 0.42 in Figure 2) such that $q_{1}^{*}$ increases with $\alpha$, while $w_{1}^{*}$ decreases with $\alpha$ when $\alpha$ is smaller than 0.42 . However, $q_{1}^{*}$ and $w_{1}^{*}$ keep constant when $\alpha$ is larger than 0.42 . The reasons behind this can be explained as follows. As the supplier sells a small part of $\mathrm{AR}$, his production capacity constraint still binds. In this case, a higher factoring ratio means that more capital can be used for production, leading to more production quantity and higher financing ability of trade credit. Then, to induce the retailer to procure more, the supplier would reduce wholesale price. On the other hand, as the supplier sells a large part of AR, production capacity constraint is relaxed. This case reduces to trade credit financing problem without capital constraints on supply side. Then, the financing ability of trade credit can be enhanced to $100 \%$. 
a)

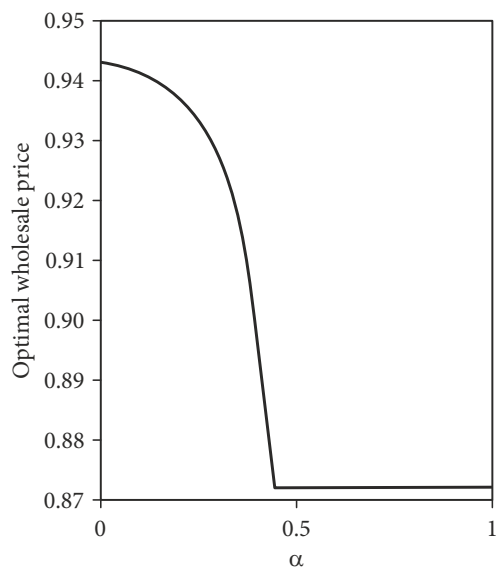

c)

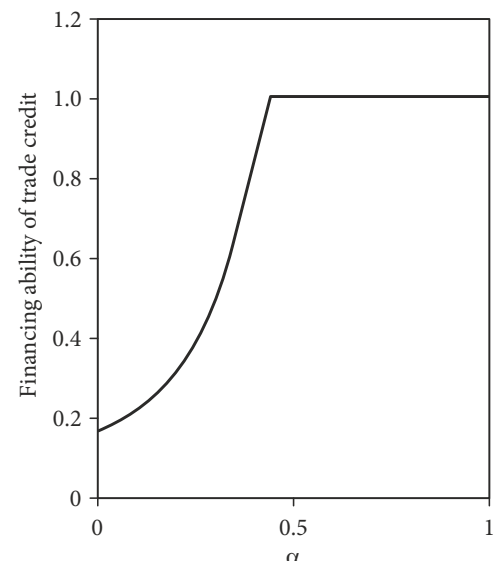

b)

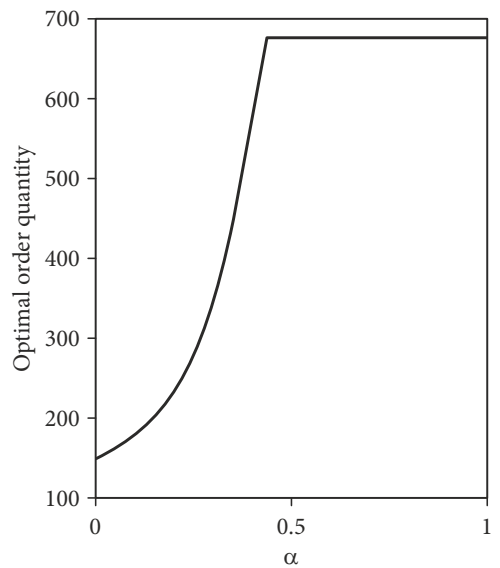

d)

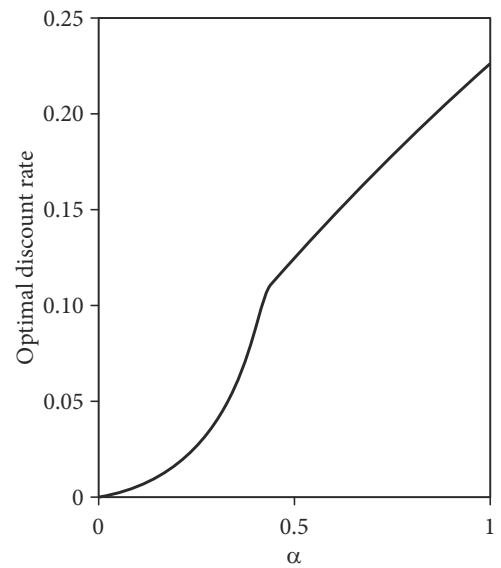

Figure 2. Impact of $\alpha$ on optimal decisions

\subsection{Comparison with the single trade credit strategy}

Before making comparisons, we first consider a special case with $\alpha=1$, namely the supplier sells the whole AR. According to the analysis in above section, the supplier's expected profit changes to be $\pi_{1}^{S}\left(w_{1}\right)=(1-\delta) y_{1}+B_{R}-c q_{1}$. Clearly, $(1-\delta) y_{1}+B_{R}-c q_{1}>0$ should hold, otherwise the supplier has no incentive to offer trade credit. This implies that the production constraint for the supplier (i.e., inequality (8)) is relaxed. Thus, it is easy to ensure that the optimal operational decisions (denoted by $\left(w_{1}^{*}, q_{1}^{*}\right)$ ) under full factoring strategy are $\left(w^{N}, q^{N}\right)$. Correspondingly, the associated profits for the supplier and the retailer are:

$$
\begin{aligned}
& \pi_{1}^{S}\left(w_{1}^{*}\right)=\int_{0}^{w^{N} q^{N}-B_{R}} \bar{F}(x) d x+B_{R}-c q^{N} ; \\
& \pi_{1}^{R}\left(q_{1}^{*}\right)=\int_{w^{N} q^{N}-B_{R}}^{q^{N}} \bar{F}(x) d x-B_{R} .
\end{aligned}
$$

Corollary 1. Comparing with single trade credit strategy, full factoring strategy brings lower wholesale price, higher production quantity, and more expected profits for the supplier and retailer. 
Corollary 1 states that a capital-constrained supplier actually benefits from selling the whole AR. It is reasonable considering that selling the whole AR is a kind of financing method for the supplier. In the presence of capital constraint, the supplier only provides a suboptimal credit size to the retailer. As a result, the retailer has to procure a suboptimal quantity $q_{0}^{*}$ in comparison with capital-unconstrained environment. When the supplier sells the whole of AR, his capital restriction is relaxed fully. This allows the supplier to offer a large credit size, and thus the order quantity can be enlarged. Additionally, note that the retailer's credit risk is fully transferred to the factor. Therefore, the wholesale price is reduced, and then the retailer can also benefit from full factoring strategy.

It is worth noting that the full factoring strategy in this paper is a little different from regular bank loan. With bank credit, the supplier is generally allowed to borrow what he needs at most, due to some reasons like bank regulations. With full factoring, however, the supplier has to sell the whole AR, which may increase his financing costs. So, does the supplier performs better if he use partial factoring strategy (i.e., the division of AR)?

Corollary 2. In a fairly priced factoring market, for the supply chain with mild capital constraints (i.e., $\left.\bar{\alpha}\left(B_{S}, B_{R}\right) \leq c\right)$, (1) when $\alpha<\bar{\alpha}\left(B_{S}, B_{R}\right)$, full factoring outperforms partial factoring, and the latter outperforms single trade credit strategy; (2) when $\alpha \geq \bar{\alpha}\left(B_{S}, B_{R}\right)$, partial factoring strategy is equivalent to full factoring strategy.

Corollary 2 presents that it is unnecessary for the supplier to divide AR when he has small financial requirements. This result may arise from the fairly-pricing assumption. Under this assumption the purpose of the factor charging the supplier is only to compensate the retailer's default risk due to low realized demand. Such the zero-profit nature of the factor leads to no profit loss for the supplier with small financial needs if he overly uses factoring service. When the supply chain is highly limited by capital shortage (i.e., $\bar{\alpha}\left(B_{S}, B_{R}\right)$ shifts to be higher than $c$ ), considerable simulations in subsection 4.1 demonstrate that the dominance of full factoring over partial factoring does not change.

Next, we use numerical simulations to test the robustness of our results.

Simulation example 2. All parameters are the same to simulation example 1 except that $B_{R} \in\{50,65,80,95,110\}$ in this example. Mathematically, single trade credit strategy corresponds to hybrid strategy with $\alpha$ approaching to zero; full factoring strategy corresponds to hybrid strategy with $\alpha$ equaling to one; and partial factoring strategy corresponds to hybrid strategy with $\alpha$ locating in the intermediate region between zero and one. Two important observations can be found in Figure 3.

Firstly, factoring is generally beneficial to supply chain partners, and higher factoring ratio creates higher value. In particular, there exists a threshold effect for factoring. That is, partial factoring is inferior to full factoring when $\alpha$ is smaller than a critical value. In this case, the supplier's capital constraints still bind. However, when $\alpha$ is larger than this critical value, partial factoring strategy is equivalent to factoring strategy for supply chain partners. In this sense, an account receivable owner has no incentive to divide AR.

Secondly, the retailer's capital level exerts a critical impact on each partner's performance, whereas does not affect the dominance of full factoring over partial factoring. Factoring benefits the supplier more if he trades with the retailer with lower capital, and in turn benefits 
a)

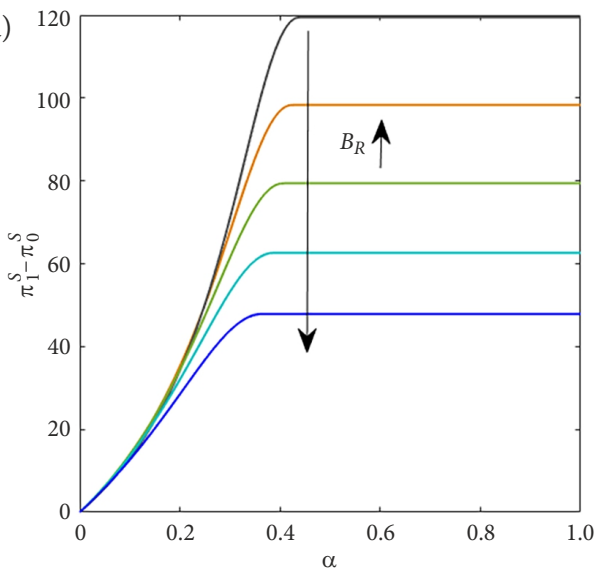

b)

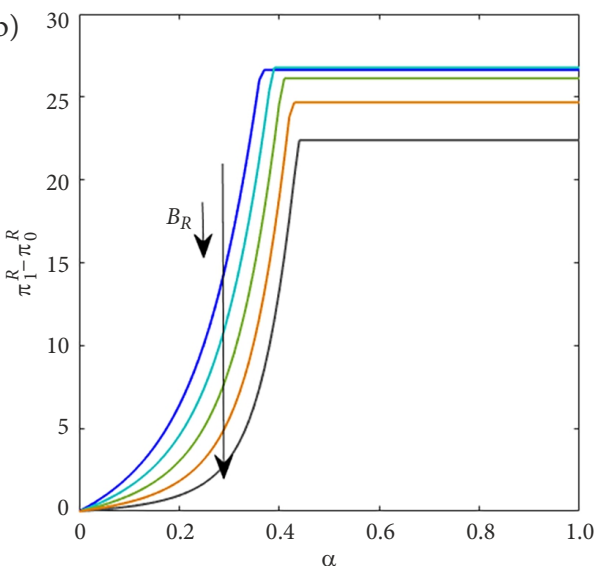

Figure 3. Impact of the retailer's capital level for any division of AR

the retailer more if the retailer has higher capital. The intuitive reason is that the supplier can take advantage of the retailer's financial weakness to earn benefit. The higher capital the retailer is endowed with, the less profit the supplier can extract.

\section{Further discussions: Imperfect factoring market}

The conclusions in previous section are gained by assuming perfect financial market. However, in practice, there exist frictions in the financial market for many reasons such as agency problem, financial distress costs, taxes, etc. In this section, we therefore consider two extensions to investigate the applicability of our results.

\subsection{Factoring market with bankruptcy costs}

It is natural in practice that the remaining assets are subject to loss when a borrower declares bankruptcy. Now, we parameterize the effect of bankruptcy costs by introducing a parameter $\beta \in(0.1]$ to denote the marginal bankruptcy costs as the work in Yang and Birge (2017). Specifically, a part of $\beta$ of the realized revenue is assumed to be lost when the retailer bankrupts (i.e., $X<y_{1}$ ). As $\beta$ approaches to zero, the model in this subsection reduces to the previous model.

Based on the credit priority assumption, the factor obtains $\min \left\{(1-\beta) X, \alpha y_{1}\right\}$ when bankruptcy occurs; otherwise, it collects the payment of $\alpha y_{1}$. Clearly, the factor's expected revenue depends on the factoring ratio $\alpha$ as well as marginal bankruptcy cost $\beta$. In particular, the factor's pricing equation can be written as follows based on default types ${ }^{1}$.

\footnotetext{
${ }^{1}$ Retailer defaults when she cannot repay the whole liabilities, namely, $X<y_{1}$. Since the liabilities to the factor is assumed to repay first, then two types rise. One is that only the liabilities to the supplier default, or equivalently, $\alpha<1-\beta$. The other one is that both the liabilities to the supplier and factor default, or equivalently, $\alpha \geq 1-\beta$.
} 
Type 1: only the liabilities to the supplier have default risk $(\alpha<1-\beta)$,

$$
(1-\beta) \int_{0}^{\alpha y_{1} /(1-\beta)} \bar{F}(x) d x=(1-\delta) \alpha y_{1} .
$$

Type 2: both liabilities to the supplier and the factor have default risk $(\alpha \geq 1-\beta)$,

$$
(\alpha+\beta-1) y_{1} \bar{F}\left(y_{1}\right)+(1-\beta) \int_{0}^{y_{1}} \bar{F}(x) d x=(1-\delta) \alpha y_{1} .
$$

On the other hand, the supplier's expected profit can be adjusted as,

$$
\pi_{1}^{S}\left(w_{1}\right)=(1-\beta) \int_{0}^{y_{1}} \bar{F}(x) d x+B_{R}-c q_{1}+\beta y_{1} \bar{F}\left(y_{1}\right) .
$$

Combining Eq. (3), (10) and (11), the optimal decisions can be established when bankruptcy costs exist. The implicit expressions was left in the Appendix (see (A10)-(A12)). The following Proposition characterizes the joint impact of the bankruptcy costs and factoring ratio.

Proposition 5. When bankruptcy costs exist, for the supply chain with mild capital constraints and high marginal bankruptcy costs (i.e., $\left.\max \left\{\tilde{\alpha}\left(B_{S}, B_{R}, \beta\right), \hat{\alpha}\left(B_{S}, B_{R}, \beta\right)\right\} \leq c\right)$, we have: (1) the marginal bankruptcy costs $\beta$ gives a negative impact on the supplier's expected profit; (2) there exists a threshold value (either $\tilde{\alpha}\left(B_{S}, B_{R}, \beta\right)$ or $\left.\hat{\alpha}\left(B_{S}, B_{R}, \beta\right)\right)$ such that the factoring ratio $\alpha$ gives a positive impact on the supplier's expected profit when $\alpha$ is smaller than this value whereas has no impact on it when $\alpha$ is larger than this value.

In Proposition 5, both $\tilde{\alpha}\left(B_{S}, B_{R}, \beta\right)$ and $\hat{\alpha}\left(B_{S}, B_{R}, \beta\right)$ are the factoring ratio bounds between capital-constrained operations and capital-unconstrained operations ${ }^{2}$. Proposition 5 demonstrates that the supplier with small financial needs still benefits more from selling the whole AR than partial AR, even the factoring market shifts to be imperfect with bankruptcy costs. In practice, the supplier is likely to divide AR especially when he has low capital requirements in order to reduce financing costs. Propositions 4 and 5 consistently indicate that dividing AR is not favorable for the supplier.

As in Proposition 4, we still cannot obtain desirable analytical results for the supplier with high financing demand and low bankruptcy costs. In tuition, high financing needs along with low bankruptcy frictions will further discourage the supplier from dividing AR. Actually, our considerable numerical computations have confirmed this point. Next, we use numerical simulations to investigate the robustness of our results.

Simulation example 3. In this simulation, we examine how bankruptcy costs affect supply chain performance by varying the value of $\beta$. Also, we explore where the optimal $\alpha$ may be located by changing $\alpha$ from zero to one. Let $B_{S}=10, B_{R}=50, \beta \in\{0,0.1,0.2,0.3,0.4\}$. $\beta=$ 0 represents perfect factoring market and other values of $\beta$ represent imperfect factoring market with bankruptcy costs. Other parameters are set as the same to example 1 .

\footnotetext{
$2 \tilde{\alpha}\left(B_{S}, B_{R}, \beta\right)$ and $\hat{\alpha}\left(B_{S}, B_{R}, \beta\right)$ are defined in the proof of Proposition 5 in the Appendix. It can be shown that $\tilde{\alpha}\left(B_{S}, B_{R}, \beta\right)$ and $\hat{\alpha}\left(B_{S}, B_{R}, \beta\right)$ decrease with $B_{S}$ and $B_{R}$, as well as $\beta$. Hence, when $B_{S}$, $B_{R}$ and $\beta$ are high enough such that $\max \left\{\tilde{\alpha}\left(B_{S}, B_{R}, \beta\right), \hat{\alpha}\left(B_{S}, B_{R}, \beta\right)\right\} \leq c$, we can obtain analytical properties related to the joint impact of the bankruptcy costs and factoring ratio.
} 
a)

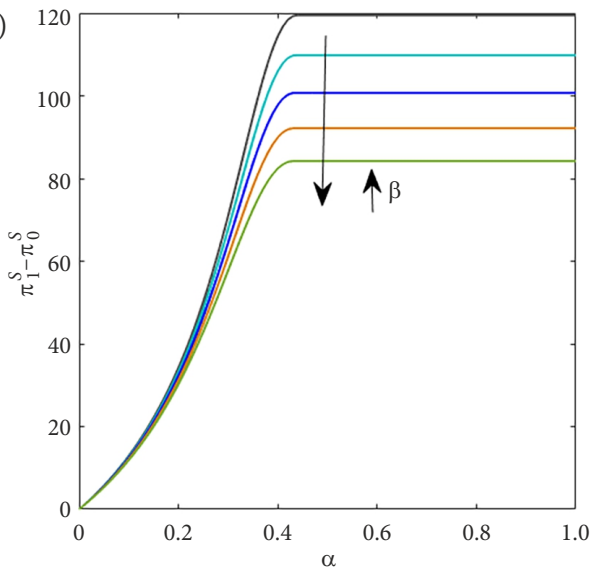

b)

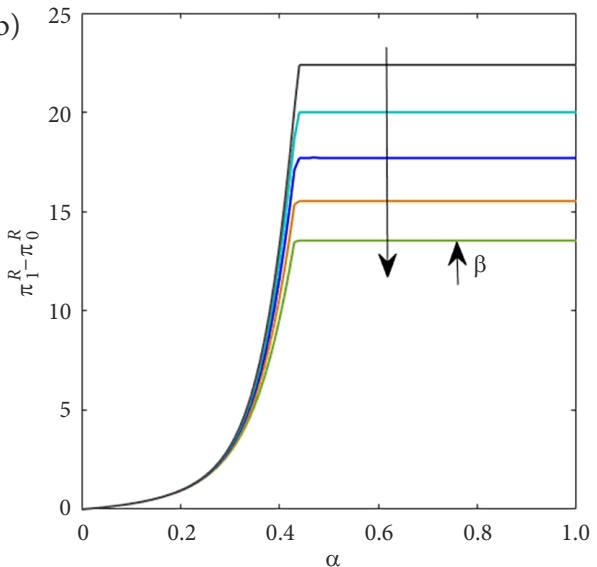

Figure 4. Impact of bankruptcy costs for any division of AR

Observation 1. In the fairly priced factoring market, the existence of bankruptcy costs dampens supply chain performance and the value of factoring, but cannot incentivize the supplier to divide $A R$.

In tuition, the arise of bankruptcy costs may increase the supplier's financing costs, leading him to divide AR. By contrast, partial factoring cannot create more value for the supplier comparing with full factoring, as shown in Figure 4. This may be due to the assumption of fairly priced factoring market. With this assumption, the factor earns zero profit. Thus, the supplier uses factoring to finance production like using his own capital.

Yang and Birge (2017) also investigate the impact of bankruptcy costs and the retailer's capital level, but we examine them under different problem scenarios. They concentrate on whether and under what condition the supplier has incentive to share risk with the bank. Their findings are that the supplier wants to share some risk with the bank under environment with high bankruptcy costs and low retailer's capital level. That leads to the retailer use the combination of trade credit and bank loan. Our paper, however, focuses on to what extent the supplier would like to divide AR. Our simulation results show that the supplier is willing to sell the whole AR in order to finance the retailer without access to bank loan.

\subsection{Factoring market with strategic pricing}

In our previous analysis, the factoring is assumed to be priced fairly in order to obtain closedform solutions. Under some circumstances, factors operate to maximize their profits rather than earning zero profit. Hence, we next relax fairly pricing assumption by allowing the factor to engage in strategic pricing.

Under the modified modeling framework, the supplier, retailer and factor play a threestage Stackelberg game, where the factor is the first leader and the supplier is the second leader. Repeating the analysis in Section 4, we are able to obtain the supplier's and retailer's response functions. Back to the first stage, the factor chooses a discount rate to maximize its expected profit (denoted by $\pi_{1}^{f}(\delta)$ ), which can be formulated as: 


$$
\max _{\delta \in(0, \bar{\delta}]} \pi_{1}^{f}(\delta)=\delta \alpha y_{1}-\int_{0}^{\alpha y_{1}} F(x) d x .
$$

Here, the upper bound $\bar{\delta}$ captures the factor's pricing ability. A higher value of $\bar{\delta}$ indicates stronger pricing ability of the factor. With the consideration of participation constraints and financial regulations, we assume that $\bar{\delta}<1$. It is pretty hard to present analytical solutions for the three-stage Stackelberg game, we therefore turn to numerical studies to give insights. Actually, we have conducted considerable experiments regarding the impact of $\alpha$ on the optimal factoring discount rate as well as the factor's performance. In what follows, we focus on analyzing the impact of $\alpha$ on supply chain performance and resulting division of AR.

Simulation example 4. In this simulation, we examine how the factor's pricing ability affects supply chain performance and the potential division decision of AR. Let $B_{S}=10, B_{R}=$ $50, \bar{\delta} \in\{0.30,0.36,0.42\}$. The rest of parameters are set as the same to example 1 .

Observation 2. When factoring market shifts to be priced strategically, partial factoring strategy may outperform full factoring for the supplier, depending on the factor's pricing ability. More specifically, the supplier has an incentive to divide $A R$ as the strategic factor has strong pricing ability.

As illustrated in Figure 5, given any division of AR (i.e., $\alpha$ is fixed), we observe that the factor's pricing ability (measured by $\bar{\delta}$ ) affects supply chain performance and the value of factoring negatively. Unlike fairly factoring pricing, the optimal factoring strategy for the supplier may be partial factoring or full factoring, depending on the factor's pricing ability. When the factor has weak pricing ability, e.g., $\bar{\delta}=0.30$, the optimal factoring discount rate could not be too high, thus the supplier earns more if factoring the whole AR than the part of it. On the contrary, as the factor has strong pricing ability, the supplier benefits more if choosing partial factoring strategy. For example, the supplier performs the best if he chooses the factoring ratio as $\alpha=0.6$ in the case of $\bar{\delta}=0.42$. This conclusion explains why some firms in practice would like to divide their account receivables.

a)

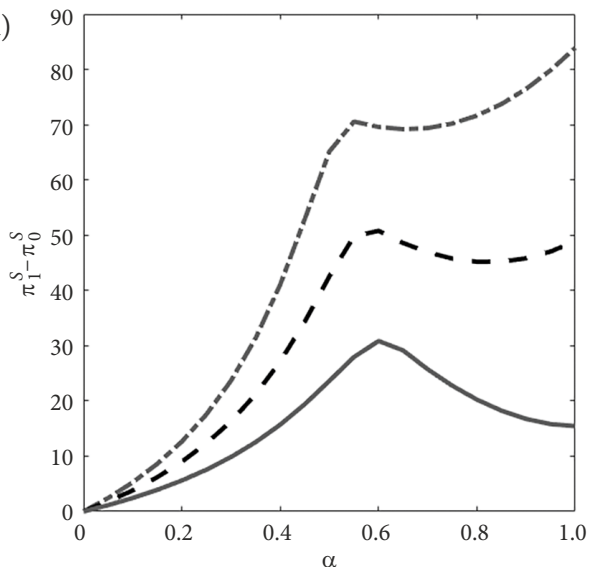

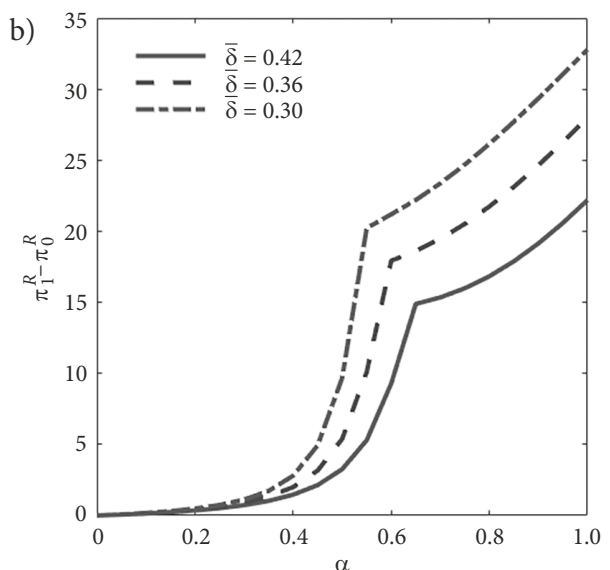

Figure 5. Impact of factor's pricing ability for any division of AR 
Indirectly, the division of the supplier's AR affects the retailer's financing mode. Financially, without factoring, the retailer's creditor is the supplier. With the introduce of factoring, the retailer's creditor has been changed. Specifically, the retailer's creditor shifts to be the factor when the supplier chooses full factoring; and to be both the supplier and factor when the supplier chooses partial factoring. Kouvelis and Zhao (2018) find that the supplier's credit rating serves as a driven factor to affect the retailer's financing structure. Concentrating on the division of the supplier's AR, we find that the factor's financing ability may act as a driven factor to indirectly influence the retailer's financing mode.

Simulation example 5. In this simulation, we test how supply chain capital level affects supply chain performance and the potential division decision of AR. $\bar{\delta}$ is fixed at 0.42 . Let $B_{S} \in\{10,50,100\}$ and $B_{R}=50$ as we investigate the impact of $B_{S}$. Similarly, let $B_{R} \in\{50,90,130\}$ and $B_{S}=10$ as we investigate the impact of $B_{R}$.

Observation 3. In most case, the supply chain capital endowment exerts a negative impact on the supplier's factoring willingness. More specifically, the supplier has no incentive to factor $A R$ when the supply chain capital endowment is high, but is willing to sell a portion of $A R$ when the supply chain capital endowment is low.

Figure 6(a) and (b) show the impacts of the retailer's capital level $B_{R}$ and the factoring ratio $\alpha$ on the value of factoring. Overall, how $\alpha$ affects the value of factoring highly depends on $B_{R}$. When $B_{R}$ is large, the difference between factoring and without factoring is smaller than zero. Thus, it is not beneficial for the supplier to sell AR. When $B_{R}$ is small, partial factoring is the best choice for the supplier. At the same time, a higher capital level leads to a lower optimal factoring ratio. For example, as depicted in Figure 6(a), the optimal factoring ratio should be 0.42 when $B_{R}=90$, while being 0.6 when $B_{R}=50$. For the retailer, we observe from Figure 6(b) that factoring generally brings benefits to her, since factoring is able to enlarge supply quantity.

Combining Figure 6(c) and (d), it can be found that a higher level of $B_{S}$ also discourages the supplier from selling more portion of AR. For example, in the case of $B_{S}=100$, the best choice for the supplier is to forgo factoring strategy and purely use internal capital level. As $B_{S}$ decreases, the supplier would like to sell a portion of his AR.

Further, factoring always benefits the retailer, and the benefits highly depend on the supply chain capital level and the factoring ratio. When the supply chain capital level is small, partial factoring is dominated over full factoring; and the reverse holds when the supply chain capital level is high. For example, in Figure 6(b), the retailer prefers full factoring if $B_{R}=50$ and prefers partial factoring if $B_{R}=130$. Moreover, if $\alpha$ is small, the retailer benefits more as supply chain capital increases; if $\alpha$ is large, the retailer benefits more as supply chain capital decreases. This can be explained as follows. As $\alpha$ is small, the supplier's production capacity is still constrained by the supply chain capital level. In this case, a higher $B_{S}$ or $B_{R}$ serves to enhance production capacity, which increases the factoring value from the retailer's side. However, as $\alpha$ increases to exceed a threshold value, production capacity constraint is relaxed, and the increase of $B_{S}$ or $B_{R}$ will increase the retailer's procurement costs, and weakens the factoring value from the retailer's perspective. 
a)

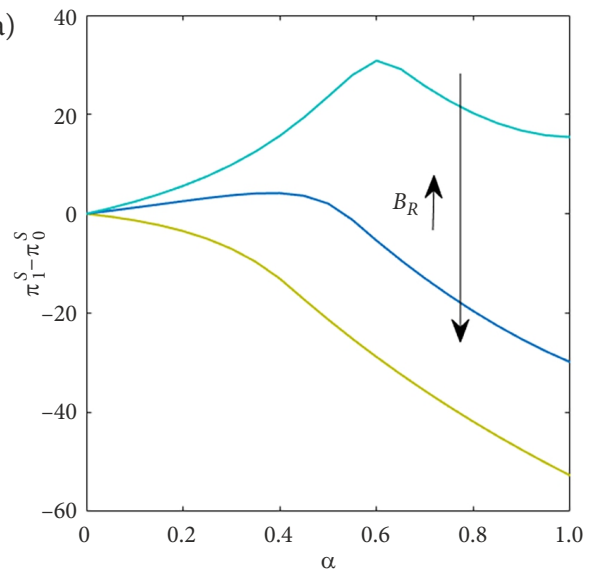

c)

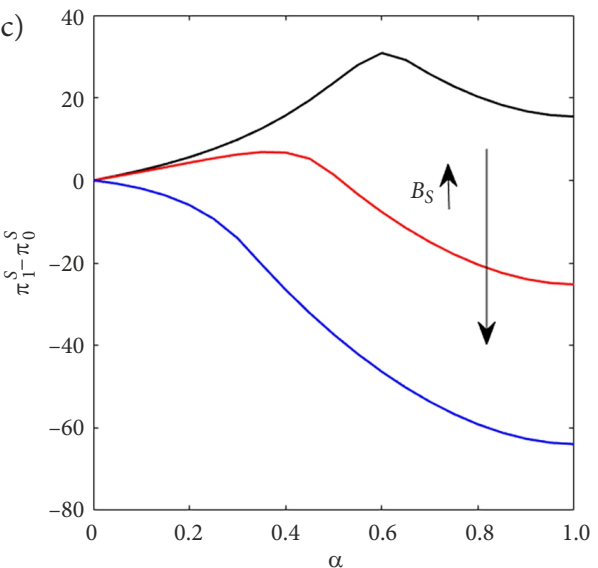

b)

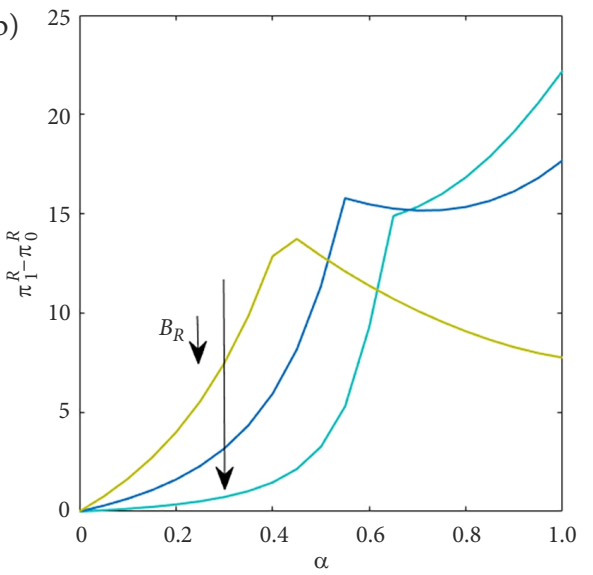

d)

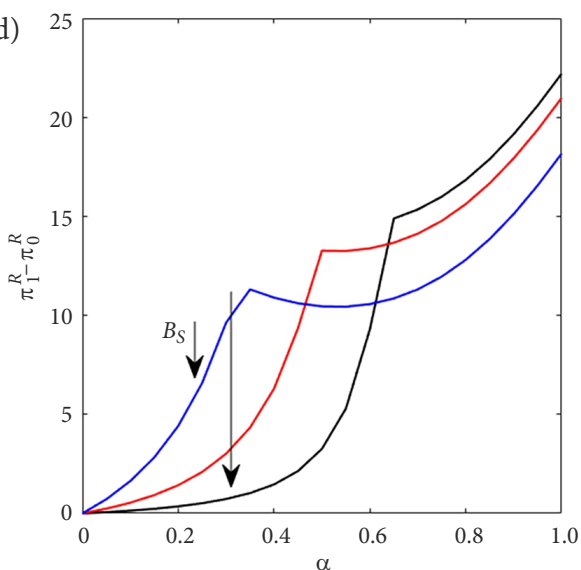

Figure 6. Impact of supply chain capital level for any division of AR

\section{Conclusions}

In this paper, we extend the traditional trade credit model to a hybrid model to study the firms' interactions of operations and financing in a supply chain setting, where a financially disadvantaged supplier sells to a capital-constrained retailer. The retailer is limited to access bank credit. We explore how the supplier uses his AR to finance his own and the retailer's inventory, and whether the division of AR is really beneficial for the supplier. Building on the stylized Stackelberg game with the supplier as the leader, we derive the operational and financing decisions for each involved member under the single trade credit strategy and the hybrid strategy evolved from trade credit. Furthermore, these strategies are compared from different perspectives of the supply chain, analytically and numerically.

Our model provides a theoretical explanation for the prevalence of factoring and has several managerial implications. First, we demonstrate that the financing advantage of trade credit can be limited by the trade creditor's financial status. The limitation can be mitigated, 
however, by factoring. Specifically, the supplier may benefit from selling it partially or fully to a third-party factor for immediate cash, rather than keeping the AR to the end of the selling season. In this way, the supplier is expected to enhance his own or the entire supply chain's performance. Second, we show that many factors such as the bankruptcy costs and the supply chain capital's level, work simultaneously to affect the supply chain member's performance, and eventually the benefits of factoring. Third, considerable numerical simulations report that it is not necessary for the supplier to divide AR when factoring is fairly priced; on the contrary, he has an incentive to divide AR when factoring is priced by a strategic factor with strong pricing ability.

This paper can be extended in several directions. First, in our model, the retail price is assumed to be fixed, which is justified by complete competition among retail markets. It would be interesting to investigate the joint decisions of pricing and financing for the retailer when trade credit is offered. Second, Due to the limitation of data availability, we focus on theoretical and numerical analysis in this paper. In the future, we will try to collect empirical data on trade credit terms and factoring ratio, and use the methods of econometrics to look into the validity of our results.

\section{Acknowledgements}

The authors thank Qinhong Zhang for constructive comments and suggestions for this paper. They are grateful to Yunzhou Zhu for insights regarding industry practice.

\section{Funding}

This work was supported by the < the National Natural Science Foundation of China (NSFC) under Grant [71802176]; Humanities and Social Sciences of Ministry of Education under Grant <18YJC630060, 19YJC790028>.

\section{Author contributions}

Wei JIN conceived the study and was responsible for the design and development of the model analysis, as well as wrote the first draft of the article. During the revision, Chengfu Wang joined in helping answer the tricky questions.

\section{Disclosure statement}

The authors claim that none of the material in the paper has been published or is under consideration for publication elsewhere. Also, they do not have any competing financial, professional, or personal interests from other parties. 


\section{References}

Buzacott, J. A., \& Zhang, R. Q. (2004). Inventory management with asset-based financing. Management Science, 50(9), 1274-1292. https://doi.org/10.1287/mnsc.1040.0278

Chen, Z., \& Zhang, R. (2019). A cash-constrained dynamic lot-sizing problem with loss of goodwill and credit-based loan. International Transactions in Operational Research, 00(2019), 1-26. https://doi.org/10.1111/itor.12675

Chod, J. (2016). Inventory, risk shifting, and trade credit. Management Science, 63(10), 3207-3225. https://doi.org/10.1287/mnsc.2016.2515

Chod, J., Lyandres, E., \& Yang, S. A. (2019). Trade credit and supplier competition. Journal of Financial Economics, 131(2), 484-505. https://doi.org/10.1016/j.jfineco.2018.08.008

Dada, M., \& Hu, Q. (2008). Financing newsvendor inventory. Operations Research Letters, 36(5), 569573. https://doi.org/10.1016/j.orl.2008.06.004

Do, T. M. H. (2018). Factoring as a form of financing small and medium-sized enterprises in ASEAN. Applied Economics and Finance, 5(3), 59-64. https://doi.org/10.11114/aef.v5i3.3175

Giannetti, M., Burkart, M., \& Ellingsen, T. (2011). What you sell is what you lend? Explaining trade credit contracts. The Review of Financial Studies, 24(4), 1261-1298. https://doi.org/10.1093/rfs/hhn096

Gong, X., Chao, X., \& Simchi-Levi, D. (2014). Dynamic inventory control with limited capital and short-term financing. Naval Research Logistics, 61(3), 184-201. https://doi.org/10.1002/nav.21576

Huang, J., Yang, W., \& Tu, Y. (2019). Supplier credit guarantee loan in supply chain with financial constraint and bargaining. International Journal of Production Research, 57(22), 7158-7173. https://doi.org/10.1080/00207543.2019.1581386

Jin, W., Zhang, Q., \& Luo, J. (2018). Non-collaborative and collaborative financing in a bilateral supply chain with capital constraints. Omega, 88, 210-222. https://doi.org/10.1016/j.omega.2018.04.001

Kiisel, T. (2013). Factoring. In Getting a business loan (pp. 93-99). Apress, Berkeley, CA. https://doi.org/10.1007/978-1-4302-4999-3_9

Klapper, L. (2006). The role of factoring for financing small and medium enterprises. Journal of Banking \& Finance, 30(11), 3111-3130. https://doi.org/10.1016/j.jbankfin.2006.05.001

Kouvelis, P., \& Zhao, W. (2011). The newsvendor problem and price-only contract when bankruptcy costs exist. Production and Operations Management, 20(6), 921-936. https://doi.org/10.1111/j.1937-5956.2010.01211.x

Kouvelis, P., \& Zhao, W. (2012). Financing the newsvendor: Supplier vs. bank, and the structure of optimal trade credit contracts. Operations Research, 60(3), 566-580. https://doi.org/10.1287/opre.1120.1040

Kouvelis, P., \& Zhao, W. (2018). Who should finance the supply chain? Impact of credit ratings on supply chain decisions. Manufacturing \& Service Operations Management, 20(1), 19-35. https://doi.org/10.1287/msom.2017.0669

Lariviere, M. A., \& Porteus, E. L. (2001). Selling to the newsvendor: An analysis of price-only contracts. Manufacturing \& Service Operations Management, 3(4), 293-305. https://doi.org/10.1287/msom.3.4.293.9971

Li, H., Mai, L., Zhang, W., \& Tian, X. (2019). Optimizing the credit term decisions in supply chain finance. Journal of Purchasing and Supply Management, 25(2), 146-156. https://doi.org/10.1016/j.pursup.2018.07.006

Li, Y., \& Gu, C. (2018). Factoring policy with constant demand and limited capital. International Transactions in Operational Research, 00(2018), 1-19. https://doi.org/10.1111/itor.12514 
Lin, Q., \& Xiao, Y. (2018). Retailer credit guarantee in a supply chain with capital constraint under push \& pull contract. Computers \& Industrial Engineering, 125, 245-257. https://doi.org/10.1016/j.cie.2018.08.029

Lu, Q., Gu, J., \& Huang, J. (2019). Supply chain finance with partial credit guarantee provided by a third-party or a supplier. Computers \& Industrial Engineering, 135, 440-455. https://doi.org/10.1016/j.cie.2019.06.026

Mian, S. L., \& Smith, C. W. (1992). Accounts receivable management policy: Theory and evidence. The Journal of Finance, 47(1), 169-200. https://doi.org/10.1111/j.1540-6261.1992.tb03982.x

Montibeller, G., Belton, V., \& Lima, M. V. A. (2007). Supporting factoring transactions in Brazil using reasoning maps: A language-based DSS for evaluating accounts receivable. Decision Support Systems, 42(4), 2085-2092. https://doi.org/10.1016/j.dss.2004.11.011

Peura, H., Yang, S. A., \& Lai, G. (2017). Trade credit in competition: A horizontal benefit. Manufacturing \& Service Operations Management, 19(2), 263-289. https://doi.org/10.1287/msom.2016.0608

Seifert, D., Seifert, R. W., \& Protopappa-Sieke, M. (2013). A review of trade credit literature: Opportunities for research in operations. European Journal of Operational Research, 231(2), 245-256. https://doi.org/10.1016/j.ejor.2013.03.016

Sopranzetti, B. J. (1998). The economics of factoring accounts receivable. Journal of Economics and Business, 50(4), 339-359. https://doi.org/10.1016/S0148-6195(98)00008-3

Soufani, K. (2002). On the determinants of factoring as a financing choice: Evidence from the UK[J]. Journal of Economics and Business, 54(2), 239-252. https://doi.org/10.1016/S0148-6195(01)00064-9

Wang, C., Fan, X., \& Yin, Z. (2019). Financing online retailers: Bank vs. electronic business platform, equilibrium, and coordinating strategy. European Journal of Operational Research, 276(1), 343-356. https://doi.org/10.1016/j.ejor.2019.01.009

Yang, S. A., \& Birge, J. R. (2017). Trade credit, risk sharing, and inventory financing portfolios. Management Science, forthcoming. https://doi.org/10.2139/ssrn.2746645

Zha, Y., Chen, K., Yue, X., Yu, Y., \& Mukhopadhyay, S. (2019). Trade credit contract in the presence of retailer investment opportunity. Naval Research Logistics, 66,(4), 283-296. https://doi.org/10.1002/nav.21840

Zhan, J., Chen, X., \& Hu, Q. (2019). The value of trade credit with rebate contract in a capital-constrained supply chain. International Journal of Production Research, 57(2), 379-396. https://doi.org/10.1080/00207543.2018.1442946

Zhou, Y. W., Wen, Z. L., \& Wu, X. (2015). A single-period inventory and payment model with partial trade credit. Computers \& Industrial Engineering, 90, 132-145.

https://doi.org/10.1016/j.cie.2015.08.003 


\section{APPENDIX}

\section{Proof of Proposition 1}

Note that $y_{0} \triangleq w_{0} q_{0}-B_{R}<q_{0}$ should hold, otherwise the retailer has no willingness to use trade credit. This implies that $\left[S\left(q_{0}\right)-\left(w_{0} q_{0}-B_{R}\right)\right]^{+}=\left[\min \left(X, q_{0}\right)-y_{0}\right]^{+}=$ $\min \left(X, q_{0}\right)-\min \left(X, y_{0}\right)$. Recall that $\mathrm{E}\left[\min \left(X, q_{0}\right)\right]=\int_{0}^{q_{0}} \bar{F}(x) d x$ and $\mathrm{E}\left[\min \left(X, y_{0}\right)\right]=$ $\int_{0}^{y_{0}} \bar{F}(x) d x$. Thus, the retailer's optimization problem can be rewritten as:

$$
\max _{q_{0}} \pi_{0}^{R}\left(q_{0}\right)=\int_{y_{0}}^{q_{0}} \bar{F}(x) d x-B_{R}
$$

$$
\text { s. t. } w_{0} q_{0}>B_{R} \text {. }
$$

Mathematically, $\frac{\partial \pi_{0}^{R}\left(q_{0}\right)}{\partial q_{0}}=\bar{F}\left(q_{0}\right)-w_{0} \bar{F}\left(y_{0}\right)$ and $\frac{\partial^{2} \pi_{0}^{R}\left(q_{0}\right)}{\partial q_{0}^{2}}=-\bar{F}\left(q_{0}\right)\left[h\left(q_{0}\right)-w_{0} h\left(y_{0}\right)\right]<0$ at the zero point. This implies that the optimal order quantity (denoted by $q_{0}\left(w_{0}\right)$ ) exists. That is, $q_{0}\left(w_{0}\right)=\left\{q_{0}: \bar{F}\left(q_{0}\right)=w_{0} \bar{F}\left(w_{0} q_{0}-B_{R}\right)\right\}$.

Next, we prove that $q_{0}\left(w_{0}\right)$ satisfies Proposition 1(2) by showing that $\frac{\partial q_{0}^{N}\left(w_{0}\right)}{\partial w_{0}}<0$ and $\frac{\partial q_{0}^{N}\left(w_{0}\right)}{\partial B_{R}}<0$. Recall that $q_{0}\left(w_{0}\right)$ is determined by the equation of $\bar{F}\left(q_{0}\right)=w_{0} \bar{F}\left(w_{0} q_{0}-B_{R}\right)$. Taking the first derivative of this equation with respect to $w_{0}$, it follows that

$$
-f\left(q_{0}\right) \frac{\partial q_{0}}{\partial w_{0}}=\bar{F}\left(y_{0}\right)-w_{0} f\left(y_{0}\right) \frac{\partial y_{0}}{\partial w_{0}} \text {. }
$$

Further, by taking a derivative of $y_{0}=w_{0} q_{0}-B_{R}$ with respect to $w_{0}$, we obtain

$$
\frac{\partial y_{0}}{\partial w_{0}}=q_{0}+w_{0} \frac{\partial q_{0}}{\partial w_{0}}
$$

Then, combining Eq. (A3) and (A2) yields

$$
\frac{\partial q_{0}}{\partial w_{0}}=\frac{\bar{F}\left(y_{0}\right)-w_{0} q_{0} f\left(y_{0}\right)}{w_{0}^{2} f\left(y_{0}\right)-f\left(q_{0}\right)}=\frac{1-w_{0} q_{0} h\left(y_{0}\right)}{w_{0}\left[w_{0} h\left(y_{0}\right)-h\left(q_{0}\right)\right]} .
$$

Because $w_{0} h\left(y_{0}\right)-h\left(q_{0}\right)<0$, then it is sufficient to show $1-w_{0} q_{0} h\left(y_{0}\right)>0$ to prove $\frac{\partial q_{0}^{N}\left(w_{0}\right)}{\partial w_{0}}<0$. To this end, we first present that $g\left(y_{0}\right)<1$. Taking the derivative of $q \bar{F}(q)$, we have $d(q \bar{F}(q)) / d q=\bar{F}(q)[1-g(q)]$. Because the generalized failure rate $g(q)$ is assumed to be increasing in $q$, it is easy to find that $q \bar{F}(q)$ is concave in $q$. Hence, there exists a unique value $\hat{q}$ to maximize $q \bar{F}(q)$, i.e., $1-g(\hat{q})=0$. Additionally, note that $q_{0} \bar{F}\left(q_{0}\right)=w_{0} q_{0} \bar{F}\left(y_{0}\right)>w_{0} q_{0} \bar{F}\left(w_{0} q_{0}\right)$. Using properties of concave functions, $w_{0} q_{0}<\hat{q}$ should hold. Thus, $1-g\left(w_{0} q_{0}\right)>1-g(\hat{q})=0$. Because $w_{0} q_{0} h\left(y_{0}\right)=w_{0} q_{0} h\left(w_{0} q_{0}-B_{R}\right)<g\left(w_{0} q_{0}\right)$, it follows that $1-w_{0} q_{0} h\left(y_{0}\right)>1-g\left(w_{0} q_{0}\right)>0$. Thus, $\frac{\partial q_{0}^{N}\left(w_{0}\right)}{\partial w_{0}}<0$ holds. Following the similar procedure, we obtain $\frac{\partial q_{0}\left(w_{0}\right)}{\partial B_{R}}=-\frac{h\left(y_{0}\right)}{h\left(q_{0}\right)-w_{0} h\left(y_{0}\right)}<0$. 


\section{Proof of Proposition 2}

Combing with the retailer's response function (see Eq. (3) in Proposition 1), the supplier's optimization problem can be concluded as:

$$
\max _{w_{0}} \pi_{0}^{S}\left(w_{0}\right)=\int_{0}^{y_{0}} \bar{F}(x) d x+B_{R}-c q_{0},
$$

s. t. $c q_{0} \leq B_{R}+B_{S}$. (capital constraints),

$$
\bar{F}\left(q_{0}\right)=w_{0} \bar{F}\left(w_{0} q_{0}-B_{R}\right) \text {. (the retailer's response function). }
$$

Based on the supply chain capital level $B_{R}+B_{S}$, we consider two cases.

Case 1: capital constraint is non-binding. Taking the first derivative of the supplier's expected profit with respect to $w_{0}$, and combining Eq. (A3) and (A4) yields

$$
\begin{aligned}
& \frac{\partial \pi_{0}^{S}\left(w_{0}\right)}{\partial w_{0}}=\left[\bar{F}\left(q_{0}\right)-c\right] \frac{\partial q_{0}}{\partial w_{0}}+q_{0} \bar{F}\left(y_{0}\right)= \\
& \frac{\bar{F}\left(q_{0}\right)\left[1-g\left(q_{0}\right)\right]-c\left[1-w_{0} q_{0} h\left(y_{0}\right)\right]}{w_{0}\left[w_{0} h\left(y_{0}\right)-h\left(q_{0}\right)\right]} .
\end{aligned}
$$

Using the first-order condition, we then obtain

$$
\bar{F}\left(q_{0}\right)\left[1-g\left(q_{0}\right)\right]=c\left[1-w_{0} q_{0} h\left(y_{0}\right)\right] .
$$

Combining Eq. (3) and (A5), the optimal decisions in the absence of supply constraint (denoted by $\left(w^{N}, q^{N}\right)$ ) are obtained. Let $\bar{B}_{S}\left(B_{R}\right)=c q^{N}-B_{R}$. Then, if $B_{S} \geq \bar{B}_{S}\left(B_{R}\right)$, the supplier would decide the wholesale price as $w^{N}$ and the retailer would order a quantity of $q^{N}$.

Case 2: supply constraint is binding. In this case, $w_{0}$ should be set such that $q_{0}\left(w_{0}\right)=$ $\left(B_{s}+B_{R}\right) / c \triangleq \bar{q}$. Combing with the retailer's response function, the optimal decisions in this case is easily obtained, denoted by $(\bar{w}, \bar{q})$.

\section{Proof of Proposition 3}

Define $\bar{\alpha}\left(B_{S}, B_{R}\right)=\left\{\alpha \in(0,1): c q^{N}=B_{S}+B_{R}+\int_{0}^{\alpha\left(w^{N} q^{N}-B_{R}\right)} \bar{F}(x) d x\right\}$.

Note that $\mathbb{E}\left[\min \left(S\left(q_{1}\right), \alpha y_{1}\right)\right]=\int_{0}^{\alpha y_{1}} \bar{F}(x) d x$, then the factor's pricing equation is equivalent to $\int_{0}^{\alpha y_{1}} \bar{F}(x) d x=(1-\delta) \alpha y_{1}$. Thus, the supplier's optimization problem can be rewritten as:

$$
\max _{w_{1}} \pi_{1}^{S}\left(w_{1}\right)=\int_{0}^{y_{1}} \bar{F}(x) d x+B_{R}-c q_{1} \text {, }
$$

s. t. $c q_{1} \leq B_{S}+B_{R}+\int_{0}^{\alpha y_{1}} \bar{F}(x) d x$, (supply chain capital constraints),

$$
\int_{0}^{\alpha y_{1}} \bar{F}(x) d x=(1-\delta) \alpha y_{1} \text {. (fairly factoring pricing equation). }
$$

(1) Given $\alpha \in(0,1]$, when $\alpha \geq \bar{\alpha}\left(B_{S}, B_{R}\right)$, the supply chain capital constraint is relaxed. Following the same procedure in Proposition 2, it yields $\left(w_{1}^{*}, q_{1}^{*}\right)=\left(w^{N}, q^{N}\right)$. When $\alpha<\bar{\alpha}\left(B_{S}, B_{R}\right)$, the supply chain capital constraint is binding. Thus, the optimal wholesale price should be set at the constraint bound, namely satisfying $c q_{1}=B_{S}+B_{R}+\int_{0}^{\alpha\left(w_{1} q_{1}-B_{R}\right)} \bar{F}(x) d x$. Further, 
combing with the retailer's response function $\bar{F}\left(q_{1}\right)=w_{1} \bar{F}\left(w_{1} q_{1}-B_{R}\right)$, the optimal decisions in the case of $\alpha<\bar{\alpha}\left(B_{S}, B_{R}\right)$ are obtained, denoted by $\left(\bar{w}_{\alpha}, \bar{q}_{\alpha}\right)$.

(2) Based on the fairly factoring pricing equation, the optimal factoring discount rate is $\delta_{1}^{*}=1-\int_{0}^{\alpha y_{1}^{*}} \bar{F}(x) d x / \alpha y_{1}^{*}$. Here, $y_{1}^{*}=w_{1}^{*} q_{1}^{*}-B_{R}$, where $\left(w_{1}^{*}, q_{1}^{*}\right)=\left(w^{N}, q^{N}\right)$ when $\alpha \geq \bar{\alpha}\left(B_{S}, B_{R}\right)$ and $\left(w_{1}^{*}, q_{1}^{*}\right)=\left(\bar{w}_{\alpha}, \bar{q}_{\alpha}\right)$ when $\alpha<\bar{\alpha}\left(B_{S}, B_{R}\right)$.

\section{Proof of Proposition 4}

In this proof, we intend to prove the following results under the condition $\bar{\alpha}\left(B_{S}, B_{R}\right) \leq c$.

(1) When $\alpha \geq \bar{\alpha}\left(B_{S}, B_{R}\right), \partial q_{1}^{*} / \partial \alpha=\partial w_{1}^{*} / \partial \alpha=0, \partial \delta_{1}^{*} / \partial \alpha>0$ and $\partial \pi_{1}^{S}\left(w_{1}^{*}\right) / \partial \alpha=\partial \pi_{1}^{R}\left(q_{1}^{*}\right) / \partial \alpha=0$;

(2) when $\alpha<\bar{\alpha}\left(B_{S}, B_{R}\right), \partial q_{1}^{*} / \partial \alpha>0, \partial w_{1}^{*} / \partial \alpha<0, \quad \partial \delta_{1}^{*} / \partial \alpha>0, \quad \partial \pi_{1}^{S}\left(w_{1}^{*}\right) / \partial \alpha>0$, and $\partial \pi_{1}^{R}\left(q_{1}^{*}\right) / \partial \alpha>0$.

(1) Case 1: $\alpha \geq \bar{\alpha}\left(B_{S}, B_{R}\right)$. In this case, $\left(w_{1}^{*}, q_{1}^{*}\right)=\left(w^{N}, q^{N}\right)$. Note that $w^{N}$ and $q^{N}$ are independent of $\alpha$ in this case. It is easy to show that $\partial q^{N} / \partial \alpha=0, \partial w^{N} / \partial \alpha=0, \partial \pi_{1}^{R}\left(q^{N}\right) / \partial \alpha=0$, and $\partial \pi_{1}^{S}\left(w^{N}\right) / \partial \alpha=0$. In additional, it can be calculated that $\partial \delta_{1}^{*} / \partial \alpha=\int_{0}^{\alpha q^{N}} x f(x) d x /$ $\left(\alpha^{2} y^{N}\right)>0$, where $y^{N}=w^{N} q^{N}-B_{R}$.

(2) Case 2: $\alpha<\bar{\alpha}\left(B_{S}, B_{R}\right)$. In this case, $\left(w_{1}^{*}, q_{1}^{*}\right)=\left(\bar{w}_{\alpha}, \bar{q}_{\alpha}\right)$, where $\bar{w}_{\alpha}=\bar{F}\left(\bar{q}_{\alpha}\right) / \bar{F}\left(\bar{w}_{\alpha} \bar{q}_{\alpha}-B_{R}\right)$ and $\bar{q}_{\alpha}=\left(B_{s}+B_{R}+\int_{0}^{\alpha\left(\bar{w}_{\alpha} \bar{q}_{\alpha}-B_{R}\right)} \bar{F}(x) d x\right) / c$. Denote $\bar{y}_{\alpha}=\bar{w}_{\alpha} \bar{q}_{\alpha}-B_{R}$, then we have

$$
\left\{\begin{array}{l}
\left(\bar{y}_{\alpha}+B_{R}\right) \bar{F}\left(\bar{y}_{\alpha}\right)=\bar{q}_{\alpha} \bar{F}\left(\bar{q}_{\alpha}\right) \\
c \bar{q}_{\alpha}=B_{s}+B_{R}+\int_{0}^{\alpha \bar{y}_{\alpha}} \bar{F}(x) d x
\end{array}\right.
$$

Taking the first derivative of $\bar{q}_{\alpha}$ and $\bar{y}_{\alpha}$ with respect to $\alpha$, we get

$$
\left\{\begin{array}{l}
{\left[\bar{F}\left(\bar{y}_{\alpha}\right)-\bar{w}_{\alpha} \bar{q}_{\alpha} f\left(\bar{y}_{\alpha}\right)\right] \partial \bar{y}_{\alpha} / \partial \alpha=\bar{F}\left(\bar{q}_{\alpha}\right)\left[1-g\left(\bar{q}_{\alpha}\right)\right] \partial \bar{q}_{\alpha} / \partial \alpha,} \\
c \partial \bar{q}_{\alpha} / \partial \alpha=\bar{F}\left(\alpha \bar{y}_{\alpha}\right)\left[\bar{y}_{\alpha}+\alpha \partial \bar{y}_{\alpha} / \partial \alpha\right] .
\end{array}\right.
$$

Rearranging the terms, we have $\frac{\partial \bar{q}_{\alpha}}{\partial \alpha}=\frac{\bar{y}_{\alpha} \bar{F}\left(\alpha \bar{y}_{\alpha}\right)}{M(\alpha)}$, and

$$
\frac{\partial \bar{y}_{\alpha}}{\partial \alpha}=\frac{\partial \bar{q}_{\alpha}}{\partial \alpha} \cdot \frac{\bar{F}\left(\bar{q}_{\alpha}\right)\left[1-g\left(\bar{q}_{\alpha}\right)\right]}{\bar{F}\left(\bar{y}_{\alpha}\right)\left[1-\bar{w}_{\alpha} \bar{q}_{\alpha} h\left(\bar{y}_{\alpha}\right)\right]} \text {, where } M(\alpha) \triangleq c-\frac{\alpha \bar{F}\left(\alpha \bar{y}_{\alpha}\right) \bar{F}\left(\bar{q}_{\alpha}\right)\left[1-g\left(\bar{q}_{\alpha}\right)\right]}{\bar{F}\left(\bar{y}_{\alpha}\right)\left[1-\bar{w}_{\alpha} \bar{q}_{\alpha} h\left(\bar{y}_{\alpha}\right)\right]} \text {. }
$$

Because $\frac{\bar{F}\left(\bar{q}_{\alpha}\right)\left[1-g\left(\bar{q}_{\alpha}\right)\right]}{\bar{F}\left(\bar{y}_{\alpha}\right)\left[1-\bar{w}_{\alpha} \bar{q}_{\alpha} h\left(\bar{y}_{\alpha}\right)\right]}<1$, then we have $M(\alpha)=c-\frac{\alpha \bar{F}\left(\alpha \bar{y}_{\alpha}\right) \bar{F}\left(\bar{q}_{\alpha}\right)\left[1-g\left(\bar{q}_{\alpha}\right)\right]}{\bar{F}\left(\bar{y}_{\alpha}\right)\left[1-\bar{w}_{\alpha} \bar{q}_{\alpha} h\left(\bar{y}_{\alpha}\right)\right]}>$ $c-\alpha \bar{F}\left(\alpha \bar{y}_{\alpha}\right)>0$ when $\alpha \leq \bar{\alpha}\left(B_{S}, B_{R}\right) \leq c$. Naturally, $\frac{\partial \bar{q}_{\alpha}}{\partial \alpha}>0$ and $\frac{\partial \bar{y}_{\alpha}}{\partial \alpha}>0$. Note that $\bar{y}_{\alpha}=\bar{w}_{\alpha} \bar{q}_{\alpha}-B_{R}$, by taking the first derivative of this equation with respect to $\alpha$, it follows that: 


$$
\begin{aligned}
& \frac{\partial \bar{w}_{\alpha}}{\partial \alpha}=\frac{\partial \bar{q}_{\alpha}}{\partial \alpha} \cdot \frac{1}{\bar{q}_{\alpha}} \cdot\left\{\frac{\bar{F}\left(\bar{q}_{\alpha}\right)\left[1-g\left(\bar{q}_{\alpha}\right)\right]}{\bar{F}\left(\bar{y}_{\alpha}\right)\left[1-\bar{w}_{\alpha} \bar{q}_{\alpha} h\left(\bar{y}_{\alpha}\right)\right]}-\bar{w}_{\alpha}\right\}< \\
& \frac{\partial \bar{q}_{\alpha}}{\partial \alpha} \cdot \frac{1}{\bar{q}_{\alpha}} \cdot\left[\frac{c}{\bar{F}\left(\bar{y}_{\alpha}\right)}-\bar{w}_{\alpha}\right]=\frac{\partial \bar{q}_{\alpha}}{\partial \alpha} \cdot \frac{\left[c-\bar{F}\left(\bar{q}_{\alpha}\right)\right]}{\bar{q}_{\alpha} \bar{F}\left(\bar{y}_{\alpha}\right)}<0,
\end{aligned}
$$

where the last ' $<0$ ' holds since $\bar{F}^{-1}(c)$ is the optimal order quantity for the whole supply chain and $\bar{q}_{\alpha}<\bar{F}^{-1}(c)$ should hold. Further, by taking the first derivative of $\delta_{1}^{*}$ with respect to $\alpha$, we have:

$$
\frac{\partial \delta_{1}^{*}}{\partial \alpha}=\frac{\left[\bar{y}_{\alpha}+\alpha \partial \bar{y}_{\alpha} / \partial \alpha\right] \int_{0}^{\alpha \bar{y}_{\alpha}} x f(x) d x}{\alpha^{2} \bar{y}_{\alpha}^{2}}>0 .
$$

Finally, recall that $w_{1}^{*}=\bar{w}_{\alpha}$ is obtained at the constraint bound, thus $\left.\frac{\partial \pi_{1}^{S}\left(w_{1}\right)}{\partial w_{1}}\right|_{w_{1}=\bar{w}_{\alpha}}<0$ (or equivalently, $\left.\frac{\partial \pi_{1}^{S}\left(w_{1}\right)}{\partial y_{1}}\right|_{y_{1}=\bar{y}_{\alpha}}>0$ ) should hold, which implies that $\bar{F}\left(\bar{q}_{\alpha}\right)\left[1-\bar{q}_{\alpha} h\left(\bar{q}_{\alpha}\right)\right]>$ $c\left[1-\bar{w}_{\alpha} \bar{q}_{\alpha} h\left(\bar{y}_{\alpha}\right)\right]$. Then, it follows that $\frac{\partial \pi_{1}^{S}\left(\bar{w}_{\alpha}\right)}{\partial \alpha}=\left\{\frac{\bar{F}\left(\bar{q}_{\alpha}\right)\left[1-\bar{q}_{\alpha} h\left(\bar{q}_{\alpha}\right)\right]}{1-\bar{w}_{\alpha} \bar{q}_{\alpha} h\left(\bar{y}_{\alpha}\right)}-c\right\} \cdot \frac{\partial \bar{q}_{\alpha}}{\partial \alpha}>0$ and $\frac{\partial \pi_{1}^{R}\left(\bar{q}_{\alpha}\right)}{\partial \alpha}=\bar{F}\left(\bar{q}_{\alpha}\right) \underbrace{\left\{1-\frac{1-\bar{q}_{\alpha} h\left(\bar{q}_{\alpha}\right)}{1-\bar{w}_{\alpha} \bar{q}_{\alpha} h\left(\bar{y}_{\alpha}\right)}\right\}} \cdot \frac{\partial \bar{q}_{\alpha}}{\partial \alpha}>0$. Namely, $\pi_{1}^{S}$ and $\pi_{1}^{R}$ increase with $\alpha$ when $\alpha<\bar{\alpha}\left(B_{S}, B_{R}\right)$.

Proof of Corollary 1. This Corollary follows as two special cases of $\alpha=0$ and 1 from Proposition 4.

Proof of Corollary 2. This Corollary follows directly from Proposition 4.

Proof of Proposition 5. To start with, we derive the optimal operational decisions denoted by $\left(w^{b^{*}}, q^{b^{*}}\right)$. Following the similar procedure as proposition 4 , there at most exist three possible pairs for the optimal decisions, depending on the values of $\alpha, B_{S}, B_{R}$ and $\beta$.

Case 1: supply chain constraints are binding, and only the liabilities to the supplier has default risk. The optimal decisions given by $\left(\bar{w}^{b}, \bar{q}^{b}\right)$ are determined by the following equations:

where $y^{b}=w^{b} q^{b}-B_{R}$.

$$
\left\{\begin{array}{l}
\left(y^{b}+B_{R}\right) \bar{F}\left(y^{b}\right)=q^{b} \bar{F}\left(q^{b}\right), \\
c q^{b}=B_{s}+B_{R}+(1-\beta) \int_{0}^{\alpha y^{b} /(1-\beta)} \bar{F}(x) d x,
\end{array}\right.
$$

Case 2: supply chain constraints are binding and both the liabilities to the supplier and factor have default risk. The optimal decisions given by $\left(\tilde{w}^{b}, \tilde{q}^{b}\right)$ are determined by the following equations:

$$
\left\{\begin{array}{l}
\left(y^{b}+B_{R}\right) \bar{F}\left(y^{b}\right)=q^{b} \bar{F}\left(q^{b}\right) \\
c q^{b}=B_{s}+B_{R}+(\alpha+\beta-1) y^{b} \bar{F}\left(y^{b}\right)+(1-\beta) \int_{0}^{y^{b}} \bar{F}(x) d x
\end{array}\right.
$$


Case 3: supply chain capital constraints are relaxed. In this case, the optimal decisions are independent of the factoring fraction $\alpha$. The optimal decisions determined by $\left(w^{N b}, q^{N b}\right)$ are determined by the following equations:

$$
\left\{\begin{array}{l}
\left(y^{b}+B_{R}\right) \bar{F}\left(y^{b}\right)=q^{b} \bar{F}\left(q^{b}\right) \\
\bar{F}\left(q^{b}\right)\left[1-g\left(q^{b}\right)\right]=\frac{c\left[1-w^{b} q^{b} h\left(y^{b}\right)\right]}{1-\beta g\left(y^{b}\right)}
\end{array}\right.
$$

Let $\tilde{\alpha}\left(B_{S}, B_{R}, \beta\right) \triangleq\left\{\alpha>0: c q^{N b}=B_{s}+B_{R}+(1-\beta) \int_{0}^{\alpha y^{N b} /(1-\beta)} \bar{F}(x) d x\right\}$,

where $y^{N b}=w^{N b} q^{N b}-B_{R} y^{N b}=w^{N b} q^{N b}-B_{R}$ is the trade credit size when supply chain capital constraints are relaxed. Taking all possible cases together, we obtain the optimal decisions concluded in (A13) and (A14) when $\tilde{\alpha}\left(B_{S}, B_{R}, \beta\right)<1$. Next, we prove that when $\max \left\{\tilde{\alpha}\left(B_{S}, B_{R}, \beta\right), \hat{\alpha}\left(B_{S}, B_{R}, \beta\right)\right\} \leq c$, Proposition 5(1) and (2) hold.

- If $\tilde{\alpha}\left(B_{S}, B_{R}, \beta\right) \leq 1-\beta$, then

$$
\left(w^{b^{*}}, q^{b^{*}}\right)=\left\{\begin{array}{ll}
\left(\bar{w}^{b}, \bar{q}^{b}\right), & \alpha \leq \tilde{\alpha}\left(B_{S}, B_{R}, \beta\right) \\
\left(w^{N b}, q^{N b}\right), & \tilde{\alpha}\left(B_{S}, B_{R}, \beta\right)<\alpha \leq 1
\end{array} .\right.
$$

For any $\alpha \leq \tilde{\alpha}\left(B_{S}, B_{R}, \beta\right),\left(w^{b^{*}}, q^{b^{*}}\right)=\left(\bar{w}^{b}, \bar{q}^{b}\right)$.

Then, taking the first derivation of (A10) yields $\frac{\partial \bar{q}^{b}}{\partial \alpha}=\frac{\bar{y}^{b} \bar{F}\left(\alpha \bar{y}^{b} /(1-\beta)\right)}{\bar{M}(\alpha, \beta)}$ and $\frac{\partial \bar{q}^{b}}{\partial \beta}=-\frac{\int_{0}^{\alpha \bar{y}^{b} /(1-\beta)} x f(x) d x}{\bar{M}(\alpha, \beta)}$, where $\bar{M}(\alpha, \beta)=c-\frac{\alpha \bar{F}\left(\alpha \bar{y}^{b} /(1-\beta)\right) \bar{F}\left(\bar{q}^{b}\right)\left[1-g\left(\bar{q}^{b}\right)\right]}{\bar{F}\left(\bar{y}^{b}\right)\left[1-\bar{w}^{b} \bar{q}^{b} h\left(\bar{y}^{b}\right)\right]}$. Since $\alpha \leq \tilde{\alpha}\left(B_{S}, B_{R}, \beta\right) \leq c, \bar{M}(\alpha, \beta)>c-\alpha \bar{F}\left(\alpha \bar{y}^{b} /(1-\beta)\right)>0$, leading to $\frac{\partial \bar{q}^{b}}{\partial \alpha}>0$ and $\frac{\partial \bar{q}^{b}}{\partial \beta}<0$. It follows that,

$$
\left\{\begin{array}{l}
\left.\frac{\partial \pi_{1}^{S}}{\partial \alpha}\right|_{\left(w^{b^{*}}, q^{b^{*}}\right)=\left(\bar{w}^{b}, \bar{q}^{b}\right)}=\underbrace{\left\{\frac{\bar{F}\left(\bar{q}^{b}\right) \cdot\left[1-g\left(\bar{q}^{b}\right)\right] \cdot\left[1-\beta g\left(\bar{y}^{b}\right)\right]}{1-\bar{w}^{b} \bar{q}^{b} h\left(\bar{y}^{b}\right)}-c\right\} \cdot \frac{\partial \bar{q}^{b}}{\partial \alpha}>0 ;}_{>0} \\
\left.\frac{\partial \pi_{1}^{S}}{\partial \beta}\right|_{\left(w^{b^{*}}, q^{b^{*}}\right)=\left(\bar{w}^{b}, \bar{q}^{b}\right)}=-\int_{0}^{\bar{y}^{b}} x f(x) d x+\underbrace{\left\{\frac{\bar{F}\left(\bar{q}^{b}\right) \cdot\left[1-g\left(\bar{q}^{b}\right)\right] \cdot\left[1-\beta g\left(\bar{y}^{b}\right)\right]}{1-\bar{w}^{b} \bar{q}^{b} h\left(\bar{y}^{b}\right)}-c\right\}}_{>0} \cdot \frac{\partial \bar{q}^{b}}{\partial \beta}<0 .
\end{array}\right.
$$

For any $\tilde{\alpha}\left(B_{S}, B_{R}, \beta\right)<\alpha \leq 1$, then $\left(w^{b^{*}}, q^{b^{*}}\right)=\left(w^{N b}, q^{N b}\right)$. It follows that

$$
\left\{\begin{array}{l}
\left.\frac{\partial \pi_{1}^{S}}{\partial \alpha}\right|_{\left(w^{b^{*}}, q^{b^{*}}\right)=\left(w^{N b}, q^{N b}\right)}=0 ; \\
\left.\frac{\partial \pi_{1}^{S}}{\partial \beta}\right|_{\left(w^{b^{*}}, q^{b^{*}}\right)=\left(w^{N b}, q^{N b}\right)}=-\int_{0}^{y^{N b}} x f(x) d x+\underbrace{\left\{\frac{\bar{F}\left(q^{N b}\right) \cdot\left[1-g\left(q^{N b}\right)\right] \cdot\left[1-\beta g\left(y^{N b}\right)\right]}{1-w^{N b} q^{N b} h\left(y^{N b}\right)}-c\right\}}_{=0} \cdot \frac{\partial q^{N b}}{\partial \beta}<0 .
\end{array}\right.
$$


In sum, for $\tilde{\alpha}\left(B_{S}, B_{R}, \beta\right) \leq 1-\beta$ and $\tilde{\alpha}\left(B_{S}, B_{R}, \beta\right) \leq c$, we have shown that: $\frac{\partial \pi_{1}^{S}}{\partial \beta}<0$ and $\frac{\partial \pi_{1}^{S}}{\partial \alpha}>0$ when $\alpha \leq \tilde{\alpha}\left(B_{S}, B_{R}, \beta\right) ; \frac{\partial \pi_{1}^{S}}{\partial \beta}<0$ and $\frac{\partial \pi_{1}^{S}}{\partial \alpha}=0$ when $\tilde{\alpha}\left(B_{S}, B_{R}, \beta\right)<\alpha \leq 1$.

- If $1-\beta<\tilde{\alpha}\left(B_{S}, B_{R}, \beta\right)<1$, then

$$
\left(w^{b^{*}}, q^{b^{*}}\right)= \begin{cases}\left(\bar{w}^{b}, \bar{q}^{b}\right), & \alpha \leq 1-\beta \\ \left(\tilde{w}^{b}, \tilde{q}^{b}\right), & 1-\beta<\alpha \leq \hat{\alpha}\left(B_{S}, B_{R}, \beta\right) . \\ \left(w^{N b}, q^{N b}\right), & \hat{\alpha}\left(B_{S}, B_{R}, \beta\right)<\alpha \leq 1\end{cases}
$$

Here, $\hat{\alpha}\left(B_{S}, B_{R}, \beta\right) \in(1-\beta, 1)$ is the unique solution of the equation $c q^{N b}=B_{s}+B_{R}+$ $(\alpha+\beta-1) y^{N b} \bar{F}\left(y^{N b}\right)+(1-\beta) \int_{0}^{y^{N b}} \bar{F}(x) d x$. Above, we have shown that $\partial \pi_{1}^{S} / \partial \beta<0$ and $\partial \pi_{1}^{S} / \partial \alpha \geq 0$ when $\left(w^{b^{*}}, q^{b^{*}}\right)=\left(\bar{w}^{b}, \bar{q}^{b}\right)$ or $\left(w^{N b}, q^{N b}\right)$. Thus, if $1-\beta<\tilde{\alpha}\left(B_{S}, B_{R}, \beta\right)<1$, we only need to present that $\partial \pi_{1}^{S} / \partial \beta<0$ and $\partial \pi_{1}^{S} / \partial \alpha>0$ when $\left(w^{b^{*}}, q^{b^{*}}\right)=\left(\tilde{w}^{b}, \tilde{q}^{b}\right)$. Taking the first derivation of (A11) yields $\frac{\partial \tilde{q}^{b}}{\partial \alpha}=\frac{\tilde{y}^{b} \bar{F}\left(\tilde{y}^{b}\right)}{\tilde{M}(\alpha, \beta)}$ and $\frac{\partial \tilde{q}^{b}}{\partial \beta}=-\frac{\int_{0}^{\tilde{y}^{b}} x f(x) d x}{\tilde{M}(\alpha, \beta)}$, where $\tilde{M}(\alpha, \beta)=c-\frac{\alpha\left[1-(1-\beta) g\left(\bar{y}^{b}\right) / \alpha\right] \bar{F}\left(\tilde{q}^{b}\right)\left[1-g\left(\tilde{q}^{b}\right)\right]}{\bar{F}\left(\bar{y}^{b}\right)\left[1-\tilde{w}^{b} \tilde{q}^{b} h\left(\bar{y}^{b}\right)\right]}$ and $\tilde{y}^{b}=\tilde{w}^{b} \tilde{q}^{b}-B_{R}$. Considering that $0<1-(1-\beta) g\left(\tilde{y}^{b}\right) / \alpha<1$. Therefore, we have $\tilde{M}(\alpha, \beta)>c-\alpha\left[1-(1-\beta) g\left(\bar{y}^{b}\right) / \alpha\right]>0$ when $\alpha \leq \hat{\alpha}\left(B_{S}, B_{R}, \beta\right) \leq c$, which implies that $\frac{\partial \tilde{q}^{b}}{\partial \alpha}>0$ and $\frac{\partial \tilde{q}^{b}}{\partial \beta}<0$. Further,

$$
\left\{\begin{array}{l}
\left.\frac{\partial \pi_{1}^{S}}{\partial \alpha}\right|_{\left(w^{b^{*}}, q^{b^{*}}\right)=\left(\tilde{w}^{b}, \tilde{q}^{b}\right)}=\underbrace{\left\{\frac{\bar{F}\left(\tilde{q}^{b}\right) \cdot\left[1-g\left(\tilde{q}^{b}\right)\right] \cdot\left[1-\beta g\left(\tilde{y}^{b}\right)\right]}{1-\tilde{w}^{b} \tilde{q}^{b} h\left(\tilde{y}^{b}\right)}-c\right\} \cdot \frac{\partial \tilde{q}^{b}}{\partial \alpha}>0 ;}_{>0} \\
\left.\frac{\partial \pi_{1}^{S}}{\partial \beta}\right|_{\left(w^{b^{*}}, q^{b^{*}}\right)=\left(\tilde{w}^{b}, \tilde{q}^{b}\right)}=-\int_{0}^{\tilde{y}^{b}} x f(x) d x+\underbrace{\left\{\frac{\bar{F}\left(\tilde{q}^{b}\right) \cdot\left[1-g\left(\tilde{q}^{b}\right)\right] \cdot\left[1-\beta g\left(\tilde{y}^{b}\right)\right]}{1-\tilde{w}^{b} \tilde{q}^{b} h\left(\tilde{y}^{b}\right)}-c\right\}}_{>0} \cdot \frac{\partial \tilde{q}^{b}}{\partial \beta}<0 .
\end{array}\right.
$$

In sum, for $1-\beta<\tilde{\alpha}\left(B_{S}, B_{R}, \beta\right)<1$ and $\hat{\alpha}\left(B_{S}, B_{R}, \beta\right) \leq c$, we have shown that: $\frac{\partial \pi_{1}^{S}}{\partial \beta}<0$ and $\frac{\partial \pi_{1}^{S}}{\partial \alpha}>0$ when $\alpha<\hat{\alpha}\left(B_{S}, B_{R}, \beta\right) ; \frac{\partial \pi_{1}^{S}}{\partial \beta}<0$ and $\frac{\partial \pi_{1}^{S}}{\partial \alpha}=0$ when $\hat{\alpha}\left(B_{S}, B_{R}, \beta\right)<\alpha \leq 1$. 